\title{
Estrutura produtiva e indicadores de encadeamento na economia brasileira entre 2010 e 2014: uma análise multissetorial baseada no modelo insumo-produto
}

\author{
Patieene Alves Passoni ${ }^{1}$ \\ Fabio Freitas ${ }^{2}$
}

\section{RESUMO}

O objetivo desse estudo é analisar a estrutura produtiva brasileira nos anos de 2010 e 2014 e avaliar a importância das atividades econômicas usando o instrumental insumo-produto. Para tanto, serão analisados indicadores setoriais de encadeamento de Hirschman-Rasmussen (backward linkage/poder de dispersão e forward linkage/sensibilidade de dispersão) a partir do modelo insumo-produto. Tais indicadores foram calculados para produção, emprego e valor adicionado e foram analisados seu valor, o ordenamento e sua composição. Utiliza-se a Matriz insumo-produto (doravante MIP) para o ano de 2010 divulgada pelo IBGE e estima-se a MIP 2014 com base na metodologia proposta por Grijó e Berni (2006). É proposto um nível de desagregação de atividades com 19 setores. Os indicadores de encadeamentos para a produção e valor adicionado revelam importância acentuada das atividades industriais, com os quatro grupos Commodities agrícolas, Commodities industriais, Indústria tradicional e Indústria Inovativa sendo atividades-chave. Além disso, duas atividades de serviços se incluem nesse grupo: Transporte, armazenagem e correio e Informação e comunicação. Já para os indicadores de emprego, além da importância das atividades industrias, há destaque para atividades de agropecuária e serviços. Pela análise realizada nesse estudo, é muito semelhante a estrutura das atividades entre 2010 e 2014, analisada sobre o prisma proposto neste estudo. Houve, entretanto, uma tímida mudança na esquematização das atividades para o VBP e VA, permanecendo semelhante no emprego. A análise dos indicadores dos encadeamentos em conjunto com sua decomposição permite identificar não apenas o ordenamento sua importância, mas sua interação dos setores com os demais setores da economia.

Palavras-Chave: Indicadores de encadeamento. Estrutura produtiva. Economia brasileira. Matriz Insumoproduto. Anos 2010.

\begin{abstract}
The objective of this study is to analyze the Brazilian productive structure in the years 2010 and 2014 and to evaluate the importance of the economic activities using the input-output instruments. HirschmanRasmussen's sectoral linkage indicators (backward linkage/power of dispersion and forward linkage/power of sensitivity) in the input-output model. These indicators were calculated for production, employment and value added, and their value, ordering and composition were analyzed. The input-output matrix for 2010 published by the IBGE is used and the MIP 2014 is estimated based on the methodology proposed by Grijó and Berni (2006). A level of disaggregation of activities with 19 sectors is proposed. The production and value-added linkages show a marked importance of industrial activities, with the four groups Agricultural Commodities, Industrial Commodities, Traditional Industry and Innovative Industry being key activities. In addition, two service activities are included in this group: Transportation, storage and mail and Information and communication. For employment indicators, besides the importance of industrial activities, agriculture and services are highlighted. From the analysis performed in this study, it is very similar the productive structure in the Brazilian economy between 2010 and 2014, analyzed on the prism proposed in this study. There was, however, a timid change in the schematization of activities for VBP and VA, remaining similar in employment. In general, the indicators of production and value added chains show a marked importance of industrial activities. For employment indicators, besides the importance of industrial activities, agriculture and services are highlighted. The analysis of linkage indicators together with their decomposition allow the identification not only their importance order, but also their interaction of the sectors with the other sectors of the economy.
\end{abstract}

Keywords:Input-output multipliers. Productive structure. Brazilian economy. Input-Output Matrix. The 2010's.

Área 1 - Indústria e competitividade: 1.1 Dinâmicas industriais setoriais e dos sistemas de produção

JEL: C67, O14

\footnotetext{
${ }^{1}$ Doutoranda em Economia, Instituto de Economia da Universidade Federal do Rio de Janeiro (UFRJ).

${ }^{2}$ Professor do Instituto de Economia da Universidade Federal do Rio de Janeiro (UFRJ).
} 


\section{Estrutura produtiva e indicadores de encadeamento na economia brasileira entre 2010 e 2014: uma análise multissetorial baseada no modelo insumo-produto}

\section{Introdução}

O ano de 2010 encerra um período de elevado crescimento que se iniciou em 2004 explicado pelas condições externas relativamente favoráveis e por uma reorientação na política macroeconômica interna, que se mostrou importante nesse contexto (SERRANO, SUMMA, 2012; BASTOS et al 2015). A partir de 2011 (se estendendo até 2014), como menciona Serrano e Summa (2012), observa-se uma desaceleração da economia brasileira, principalmente em decorrência de mudanças na política econômica interna e da redução do crescimento das exportações por conta da desaceleração do ritmo de expansão da economia mundial. A média da taxa de crescimento entre 2010 e 2014 é de 3,38\%a.a., menor do que quando comparada ao período anterior (2004 a 2008, com média de 4,82\%a.a.).

Desde a década de 2000 os estudos para analisar a estrutura da economia brasileira ganharam grande espaço no debate econômico, em função da discussão acerca da existência e da intensidade de um processo de desindustrialização e/ou especialização regressiva.

Partindo de uma abordagem estruturalista, considera-se que o processo de desindustrialização está intrinsicamente relacionado a alterações na estrutura produtiva do país. Neste sentido, os argumentos da desindustrialização não podem estar somente associados à perda da participação da indústria no emprego e no valor adicionado, mas devem considerar também a forma pela qual a indústria se desenvolve e os vínculos e encadeamentos presentes na economia.

Muitos estudos da estrutura da economia brasileira ficaram restritos até o ano de 2009 pela mudança no sistema de contas do IBGE, que por sua vez, atrasou a divulgação dos dados das Tabelas de Recursos e Usos (TRU) e da Matriz insumo-produto (MIP) de 2010. A publicação desses dados em 2015 e 2016 respectivamente, permite analisar em mais detalhes o comportamento da estrutura produtiva brasileira depois de 2008, ano da crise internacional e seus efeitos pós-2009 no Brasil.

Buscando contribuir para o debate acerca da mudança da estrutura produtiva brasileira, o objetivo desse é analisar a estrutura produtiva brasileira e avaliar a importância das atividades econômicas a partir de uma abordagem multissetorial nos anos de 2010 e $2014^{3}$ usando o instrumental insumo-produto. Para tanto, serão analisados indicadores setoriais de encadeamento derivados dos multiplicadores associados a variações da demanda final e seus efeitos sobre os setores. Os indicadores básicos utilizados serão os de setores-chave de Hirschman-Rasmussen (backward linkage/poder de dispersão e forward linkage/sensibilidade de dispersão).

Os indicadores mencionados acima são calculados para o valor bruto da produção (VBP), emprego e valor adicionado (VA), tomando como base a matriz de Leontief que capta os efeitos diretos e indiretos de uma variação da demanda final sobre o valor da produção. Além disso, é proposta uma decomposição dos indicadores de encadeamento, com o objetivo de avaliar adequadamente o quanto a variação da demanda final de um setor afeta os demais setores na economia e o quanto um setor é afetado pela variação da demanda final dos demais setores. O uso dessa metodologia permitiu identificar não apenas o ordenamento dos encadeamentos, dado pelos valores o poder de dispersão e sensibilidade de dispersão, mas também permitiu analisar a interação dos setores com os demais setores da economia.

Além dessa introdução, este artigo possui mais cinco seções. Na segunda seção, é feito um breve panorama da literatura sobre mudança estrutural, estrutura produtiva e indicadores de encadeamento. $\mathrm{Na}$ terceira são apresentados aspectos metodológicos envolvendo o modelo insumo-produto e a base de dados utilizada. Em seguida, apresenta-se um breve panorama sobre a estrutura do valor bruto da produção entre 2010 e 2014. Na quinta são apresentados os dados dos indicadores de encadeamento e por fim, alguns comentários finais.

\footnotetext{
${ }^{3}$ Reconhece-se a importância e a riqueza de uma análise que considerasse uma temporalidade anterior à 2010, podendo ser fonte de identificação de processo de mudança estrutural na economia brasileira. Entretanto, houve uma mudança no Sistema de Contas Nacional (SCN) no ano de 2010, referência para os dados utilizados em análises insumo-produto. A comparabilidade dos dados da MIP para os anos 2000 (que estão divulgadas baseadas no SCN 2000) não pode ser realizada de maneira direta com os dados do SCN 2010. Assim, é necessário um esforço adicional para ser desenvolvidas análises de temporalidade mais extensa.
} 


\section{Mudança estrutural, estrutura produtiva e indicadores de encadeamento}

A análise da estrutura produtiva é realizada na literatura do desenvolvimento clássica sob o prisma da mudança estrutural é um dos aspectos analisados dentro da literatura do desenvolvimento, tendo sido analisada sob diversos prismas por diferentes autores (SYRQUIN, 1988). Dentre estes, pode-se analisar a estrutura a partir do ritmo de acumulação da economia, tratado por exemplo por Rostow (1960). Há ainda aqueles que analisam a composição dos setores de produção entre as diversas atividades, como Kuznets (1960) e Chenery (1968) e também sua estrutura de emprego, tais como e Fisher (1939) e Clark (1940). Outros autores analisam a estrutura a partir das relações tecnológicas, identificadas pelos coeficientes de insumo-produto, como Syrquin (1988) e Chenery (1968).

Dentre tais aspectos, Syrquin (1988) destaca que a estrutura da economia foi identificada principalmente por modificações composição da demanda, estrutura de comércio, aspectos relacionados a produção e emprego. É a partir da comparação desses aspectos que é possível identificar e caracterizar o processo de mudança estrutural. A ênfase dessa análise está na importância dos setores para a economia e a importância relativa dos diferentes tipos de bens produzidos, sendo um dos principais aspectos analisados para identificar a mudança estrutural em um país.

Analisando a mudança estrutural nesse contexto, torna-se possível identificá-la a partir de aspectos relacionados à produção, emprego e valor adicionado, verificando sua composição setorial. Uma das formas de se identificar tal procedimento é a partir da conexão existente entre os diferentes setores da economia.

Rasmussen (1956) avalia a estrutura da economia a partir dos encadeamentos intersetoriais e intrasetoriais existentes. Posteriormente, Hirschman (1958), ao desenvolver sua teoria do crescimento desbalanceado ou "desequilibrado", identifica a importância de encadeamentos criados pela demanda e bens sobre a produção nacional e os investimentos realizados, capazes de estimular a inovação e a competitividade. Neste sentido este autor utiliza tais indicadores para identificar o estímulo de criação ou ampliação da atividade econômica a partir da expansão de determinados setores, buscando estabelecer algum tipo de ranqueamento desses setores a partir dos impactos diretos e indiretos dessa expansão (LEITE, 2017).

Os indicadores de encadeamento Hirschman-Rasmussen são de dois tipos, um relacionado à demanda e outro à oferta. O backward linkage (encadeamento a montante ou para trás) se refere aos processos que ocorrem para trás de determinada atividade produtiva, pela demanda criada a partir da compra de insumos necessários para a produção. Está diretamente relacionado com a indústria de bens de capital e bens intermediários (TONER, 1999), havendo uma ligação intersetorial, no qual o crescimento de um setor, ao demandar mais insumos, promove o setor que atende a essa demanda.

Já os forward linkages (à jusante ou para frente) são aqueles em que a indústria chave tem a capacidade de criar para frente na cadeia de produção, dada sua produção para o fornecimento de inputs para outras indústrias. É um encadeamento relacionado à oferta de bens, pois, se houver um aumento de produtividade tais efeitos são repassados pelos encadeamentos para frente.

Ressalta-se que os "backward linkages effects are important not only from secondary back to primary production, but also from tertiary back to both secondary and primary production" (HIRSCHMAN, 1958, p. 116). A economia está encadeada, e quanto maior for a capacidade de produção nacional, o efeito dos encadeamentos passa a ser maior.

De acordo com Hirschman (1958), o backward linkage possui efeito mais direto, os impactos que os encadeamentos para trás geram na cadeia são mais confiáveis, pois, uma vez que que a demanda se amplie e aumente a necessidade de insumos intermediários a oferta responderia estimulando a produção de tais bens (NASSIF et al, 2016, LEITE, 2017). É possível, entretanto, que parte dessa demanda por novos insumos seja atendida por importações, mas a geração de demanda por tais insumos cria oportunidade de ampliação da produção nacional. Além disso, dada a característica dos encadeamos à jusante, ou seja, uma possibilidade de criar demanda, Hirschman (1958) ressalta estes podem não acontecer na sua "forma pura".

No tocante à economia brasileira, alguns estudos apresentam uma análise da mudança estrutural utilizando indicadores de encadeamento. Morceiro (2012), ao fazer uma análise da desindustrialização entre 2000-2011, dentre diversos indicadores, aponta o uso dos multiplicadores de produção do tipo Hirschman-Rasmussen para testar a hipótese de que houve desindustrialização no Brasil. 
Nassif et al (2015) utiliza índices de Rasmussen-Hirschman para a economia brasileira nos anos de 1996, 2000, 2005 e 2009 para verificar se houve redução do impacto da indústria brasileira nesse período. Constatam que a indústria de transformação continua sendo muito importante por consistir no setor que mantém os maiores encadeamentos para trás na economia brasileira, mas que vem perdendo capacidade de dinamizar a economia ao longo do tempo. Tais encadeamentos experimentaram seus decréscimos mais intensos entre 1996 e 2000, tendo alguns se recuperando entre 2000 e 2005. Segundo este estudo, os autores concluem que existe pouca evidência para sustentar a tese de que houve desindustrialização da economia brasileira no período.

O estudo mais recente a utilizar este tipo de indicador foi realizado por Morrone (2016) e é temporalmente o mais similar ao desse estudo. Analisa a mudança dos indicadores entres 2010 e 2013. Nesse estudo o autor busca identificar quais são os setores que tem maior capacidade de estimular a economia para retirá-la da recessão.

Morrone (2016) utiliza indicadores de encadeamento, baseado no método eigenvector desenvolvido por Dietzenbacher (1992), que possui uma medida iterativa de encadeamentos para trás e para frente, mas que são calculados pelas suas redes de demanda. Tal indicador considera os efeitos de encadeamento em várias "rodadas", captando os efeitos ao longo tempo. Baseado nesses indicadores é possível verificar alguma mudança estrutural dentre o período, em especial para alguns setores analisados (pesticidas, verniz, tinhas e lacas; metais não-ferrosos; borracha e plástico).

\section{Metodologia}

Nesta seção será a presentada a metodologia adotada neste estudo. Na primeira subseção é apresentada uma versão simples do modelo insumo-produto. Serão apresentados também os indicadores de encadeamento sob o ponto de vista deste referencial metodológico. Na segunda subseção são apresentadas a fonte de dados e a classificação das atividades utilizadas neste estudo.

\subsection{O modelo insumo-produto}

O uso do modelo insumo-produto para análise das mudanças estruturais remonta a trabalhos clássicos como Leontief (1953) e Chenery et al (1962), sendo um dos principais instrumentos utilizados na literatura econômica com esta finalidade (DIETZENBACHER; LOS, 1998).

Partindo de um modelo insumo-produto básico ${ }^{4}$ é possível determinar o valor da produção das atividades (x, de dimensão $m \times 1$, em que $m$ é o número de atividades na economia) de maneira endógena, através da matriz inversa de Leontief $\left(\mathbf{Z}=\left(\mathbf{I}-\mathbf{A}^{\mathbf{n}}\right)^{\mathbf{- 1}}\right)$. Esta é calculada a partir da matriz de coeficientes técnicos nacionais $\left(\mathbf{A}^{\mathbf{n}}, m \times m\right)$, que apresenta em suas colunas os requerimentos de insumos por unidade de valor da produção nacional de cada atividade. Assim, em $\mathbf{Z}$ são estabelecidas as quantidades de insumos direta e indiretamente necessários para a produção que atenderá a demanda final por bens produzidos domesticamente $\left(\mathbf{f}^{\mathbf{n}}, m \times 1\right)$.

$$
\mathbf{X}=\left(\mathbf{I}-\mathbf{A}^{\mathbf{n}}\right)^{-\mathbf{1}} \mathbf{f}^{\mathbf{n}}=\mathbf{Z \mathbf { f } ^ { \mathbf { n } }}
$$

Nesse modelo simples (ou aberto), toda a demanda final é considerada exógena, sendo explicada por outros fatores não presentes no modelo. A partir de (1) é possível derivar equações para a determinação do valor adicionado (como medida de renda, $\mathbf{y}$ ) e também do emprego por setor (n). No caso do emprego, o vetor do emprego setorial pode ser obtido a partir de uma matriz diagonal com os coeficientes de emprego setorial por unidade do valor da produção setorial (î) multiplicada pelo valor bruto da produção. Processo análogo pode ser observado no caso da renda, em que a matriz diagonal com os coeficientes de valor adicionado setorial por unidade de valor da produção setorial $(\widehat{\mathbf{v}})$, quando multiplicada pelo valor bruto da produção, permite a obtenção do nível de renda. Assim,

$$
\begin{gathered}
\mathbf{n}=\hat{\mathbf{l}} \mathbf{x}=\hat{\mathbf{l}} \mathbf{Z \mathbf { f } _ { \mathbf { 0 } } ^ { \mathbf { n } }}=\mathbf{L} \mathbf{f}_{\mathbf{0}}^{\mathbf{n}} \\
\mathbf{y}=\hat{\mathbf{v}} \mathbf{x}=\hat{\mathbf{v}} \mathbf{Z \mathbf { f } _ { \mathbf { 0 } } ^ { \mathbf { n } }}=\mathbf{V \mathbf { f } _ { \mathbf { 0 } } ^ { \mathbf { n } }}
\end{gathered}
$$

em que $\mathbf{L}$ é a matriz de impacto para o emprego e $\mathbf{V}$ é a matriz de impacto para o valor adicionado (renda).

\footnotetext{
${ }^{4}$ A apresentação e desenvolvimento do modelo insumo-produto básico pode ser visto em IBGE (2008), Grijó e Berni (2006), Feijó e Ramos, (2008).
} 
Assim, os elementos das matrizes de impacto ( $\mathbf{L}, \mathbf{V}$ e $\mathbf{Z})$ denotam, respectivamente, a mudança do valor da produção, do emprego e do valor adicionado no setor $i$ decorrente de uma alteração na demanda final exógena pela produção do setor $j$ (i.e, $\bar{Z}_{i j}=\partial x_{i} / \partial f_{O}^{n}{ }_{j}, \bar{L}_{i j}=\partial n_{i} / \partial f_{O}^{n}{ }_{j}, \bar{V}_{i j}=\partial y_{i} / \partial f_{O}^{n}{ }_{j}$ respectivamente).

\subsection{Indicadores de encadeamento}

Os indicadores síntese básicos calculados a partir da matriz de impacto são os indicadores de encadeamento para trás (backward linkage) e para frente (forward linkage), doravante denominados BL e FL respectivamente, também conhecidos como Hirschman-Rasmussen. O conjunto dos indicadores BL é obtido a partir matriz de impacto como segue:

$$
\mathbf{b l}=\mathbf{i}^{\prime} \Psi
$$

em que $\boldsymbol{\Psi}$ é uma matriz de impacto arbitrária $(\mathbf{L}, \mathbf{V}$ e $\mathbf{Z})$ e $\mathbf{i}$ é o vetor unitário que é operador de somatório. Segundo Rasmussen (1956, p. 134; apud. BOUCHER, 1976), este indicador indica "an estimate of the direct and indirect increase in output to be supplied by an industry chosen at random if final demand for the products of industry number $\mathrm{j}(\mathrm{j}=1, \mathrm{n})$ increases by one unit".

Os componentes do vetor bl são os indicadores BL de um setor de atividade, ou seja

$$
\mathrm{bl}_{\mathbf{j}}=\mathbf{i}^{\prime} \boldsymbol{\Psi e}_{\mathbf{j}}=\sum_{\mathbf{i}} \psi_{\mathbf{i j}}
$$

em que $\mathbf{e}_{\mathbf{j}}$ é o vetor cujo j-ésimo componente é igual a um e os demais componentes são nulos. Assim, o indicador $\mathrm{bl}_{\mathbf{j}}$ representa o impacto de uma mudança unitária na demanda final pela produção de um setor j sobre todos os setores. Este indicador permite visualizar o quanto um setor é dependente do resto da economia, tendo a capacidade dessa forma de medir os encadeamentos para trás necessários à produção de uma unidade adicional do seu produto.

Já o conjunto de indicadores de FL é dado pela seguinte expressão:

$$
\begin{gathered}
\mathbf{f l}=\boldsymbol{\Psi i} \\
\mathrm{fl}_{\mathbf{i}}=\mathbf{e}_{\mathbf{i}}^{\prime} \boldsymbol{\Psi} \mathbf{i}=\sum_{j} \psi_{\mathrm{ij}}
\end{gathered}
$$

$\mathrm{O}$ indicador $\mathrm{fl}_{\mathbf{i}}$ quantifica o impacto sobre o setor de atividade i de uma mudança exógena unitária em cada componente do vetor de demanda final.

Os dois indicadores básicos BL e FL apresentados acima são sensíveis ao número de atividades presentes na matriz, portanto não permitem a comparação entre matrizes de dimensões diferentes. Uma maneira de contornar esse problema é calcular os indicadores BL e FL médios, dividindo-se os indicadores básicos pelo número de setores $(\mathrm{m})$, obtendo-se:

$$
\begin{aligned}
\overline{\mathrm{bl}}_{\mathbf{j}} & =\left(\frac{1}{\mathrm{~m}}\right) \mathrm{bl}_{\mathbf{j}} \\
\overline{\mathrm{fl}}_{\mathbf{i}} & =\left(\frac{1}{\mathrm{~m}}\right) \mathrm{fl}_{\mathrm{i}}
\end{aligned}
$$

Uma outra forma de normalizar os indicadores de encadeamento que apresenta a vantagem adicional de facilitar as comparações dos indicadores entre atividades são os indicadores de poder de dispersão $(P d)$ e sensibilidade da dispersão $(S d)$. Os dois indicadores utilizam a média total dos coeficientes da matriz de impacto para normalizar os indicadores BL e FL médios, isto é, usam

$$
\mathrm{M}_{\text {Тот }}=\left(\frac{1}{\mathrm{~m}^{2}}\right)\left(\mathbf{i}^{\prime} \Psi \mathbf{i}\right)=\left(\frac{1}{\mathrm{~m}^{2}}\right) \sum_{\mathrm{i}} \sum_{\mathrm{j}} \Psi_{\mathbf{i j}}
$$

$\mathrm{O}$ indicador $P d$ relaciona-se com o indicador BL médio da seguinte maneira:

$$
\mathrm{Pd}_{\mathbf{j}}=\frac{\overline{\mathrm{bl}}_{\mathbf{j}}}{\mathrm{M}_{\mathrm{TOT}}}
$$

Nesse sentido, Bocher (1976) argumenta que quando $\mathrm{Pd}_{\mathrm{j}}>1$ isto indica que a indústria tem impactos significativos sobre todos os setores, ou seja, seria um setor chave, pois seu impacto sobre todos os setores é maior do que o impacto médio total e vice-versa quando $\mathrm{Pd}_{\mathrm{j}}<1$.

O indicador de sensibilidade de dispersão (Sd) é calculado de maneira análoga a partir do indicador FL médio e da média total conforme segue abaixo: 


$$
\mathrm{Sd}_{\mathrm{i}}=\frac{\overline{\mathrm{f}}_{\mathbf{i}}}{\mathrm{M}_{\mathrm{TOT}}}
$$

Segundo Schuscnny (2005), o nome de sensibilidade de dispersão é apropriado para essa situação, pois este índice reflete o quanto um setor é sensível a mudanças gerais na demanda, fornecendo a útil informação de qual o setor é mais sensível a mudanças dadas por choques de produção, emprego ou renda. Assim, quando $\mathrm{Sd}_{\mathrm{i}}>1$ isto significa que este setor terá que crescer o produto mais do que as outras indústrias para obter o aumento dado na demanda final para todo o sistema, mostrando que o setor i é mais afetado por uma expansão conjunta de todos os setores do que a média e vice-versa quando $\operatorname{Sd}_{\mathrm{i}}<1$.

Uma vez que os indicadores de poder de dispersão e sensibilidade de dispersão são medidas normalizados dos backward linkages e forward linkages, mantendo inalterado o ordenamento dos setores que geram os maiores encadeamentos, optou-se por analisar nesse estudo apenas os indicadores normalizados. Estes facilitam a análise, uma vez que os indicadores que foram maiores que 1 são interpretados como tendo encadeamento maior do que a média.

\subsection{Decomposição dos indicadores de encadeamento}

Os indicadores de encadeamento apresentados acima incluem em seu cálculo o impacto de um setor nele mesmo. Para avaliar adequadamente o quanto a variação da demanda final de um setor afeta os demais setores na economia e o quanto um setor é afetado pela variação da demanda final dos demais setores convém decompor os indicadores de encadeamento em dois termos: um termo relacionado ao próprio setor e um termo associado à influência exercida nos ou recebida dos demais setores. Podemos ainda expressar esta decomposição como uma proporção do valor total do indicador de encadeamento para permitir a definição dos setores que apresentam um encadeamento líquido da contribuição do próprio setor acima do valor médio do mesmo indicador calculado para o conjunto dos setores.

Com efeito, no caso do encadeamento para trás temos, por um lado, o impacto da variação unitária da demanda final de um setor no próprio setor como proporção do indicador de encadeamento para trás $\left(\rho_{\mathrm{i}=\mathrm{j}}\right)$ e, por outro lado, seu complemento que capta o impacto de uma variação unitária da demanda final do setor sobre demais setores da economia como proporção do indicador de encadeamento para trás $\left(\varrho_{i \neq j}\right)$, calculados conforme segue abaixo:

$$
\begin{gathered}
\rho_{i=j}=\frac{\psi_{i=j}}{\sum_{i} \psi_{i j}} \\
\varrho_{i \neq j}=1-\rho_{i=j}
\end{gathered}
$$

Para o indicador de encadeamento para frente temos, por um lado, o impacto de uma variação unitária da demanda final do setor sobre o próprio setor como proporção do valor do indicador de encadeamento para frente $\left(\rho_{\mathrm{j}=\mathrm{i}}\right)$ e, por outro lado, o seu complemento que mensura o impacto de uma variação unitária da demanda final de cada um dos demais setores sobre o setor em análise como proporção do valor do indicador de encadeamento para frente $\left(\varrho_{j \neq \mathrm{i}}\right)$ :

$$
\begin{gathered}
\rho_{j=i}=\frac{\psi_{j=i}}{\sum_{j} \psi_{i j}} \\
\varrho_{j \neq i}=1-\rho_{j=i}
\end{gathered}
$$

Os valores dos indicadores $\rho_{\mathrm{j}=\mathrm{i}}$ e $\varrho_{\mathrm{j} \neq \mathrm{i}}$ podem ser comparados com o valor médio dos impactos não relacionados com os do próprio setor nele mesmo:

$$
\varrho_{\text {med }}=\frac{\sum_{\mathrm{i}} \sum_{\mathrm{j}} \psi_{\mathrm{ij}}-\sum_{\mathrm{i}} \psi_{\mathrm{i}=\mathrm{j}}}{\sum_{\mathrm{i}} \sum_{\mathrm{j}} \psi_{\mathrm{ij}}}=1-\frac{\sum_{\mathrm{i}} \psi_{\mathrm{i}=\mathrm{j}}}{\sum_{\mathrm{i}} \sum_{\mathrm{j}} \psi_{\mathrm{ij}}}=1-\rho_{\mathrm{med}}
$$

Esta comparação visa identificar aqueles setores que geram um impacto maior ou menor do que o médio sobre os demais setores no caso do indicador de encadeamento para trás e recebem um impacto maior ou menor do que médio no caso do indicador de encadeamento para frente. Com isso, pretendemos caracterizar os setores pela sua maior ou menor interação com os demais setores da economia tanto do ponto vista dos impactos gerados como dos impactos recebidos. 


\subsection{Fonte de dados e nível de classificação}

Nessa seção apresentamos as fontes de dados, os procedimentos metodológicos para a estimação das MIP e a classificação das atividades.

Esse estudo será realizado para os anos de 2010 e 2014. A MIP para a economia brasileira é calculada pelo IBGE e tem sido divulgada nos anos com finais 0 e 5. Recentemente, a MIP foi divulgada com base no Sistema de Contas Nacionais (doravante, SCN) para o ano de $2010^{5}$. Na tentativa de preencher as lacunas dos anos para os quais as MIPs não são divulgadas oficialmente, são estimadas atualizações das MIPs oficiais para estes anos. No Brasil, existem alguns métodos que se propõem a fazer tal tarefa, tais como Guilhoto (2005; 2010), Grijó e Bêrni (2006) e Martinez (2015).

Para esse estudo foram utilizados os dados da MIP 2010 (IBGE, 2016a) e das tabelas de recursos e usos (doravante, TRUs) para o ano de 2014 (IBGE, 2016b). Para realizar a estimação da MIP a partir das TRUs segue-se a metodologia sugerida por Grijó e Berni (2006). Esta última utiliza informações estruturais presentes na MIP de 2010, que são utilizadas para estimar a MIP para o ano de $2014^{6}$, com base nas TRUs deste último ano. No Apêndice A encontram-se os procedimentos metodológicos para a adaptação do método e tratamento da base dados.

Em análises setoriais, um nível desagregado com muitas atividades torna difícil a tarefa de identificação de tendências e regularidades nos dados da economia. Nesse sentido, optou-se por utilizar um nível mais agregado do que o estimado para as matrizes, que originalmente contém 67 atividades.

O nível de desagregação utilizado para apresentação dos dados desse estudo é composto por 19 setores. Essa classificação é uma mescla dos níveis de desagregação de 12 e 20 atividades, disponível no SCN 2010 publicado pelo IBGE (2016b). O setor industrial foi desagregado com base na classificação proposta por Kupfer (2005) e Torraca e Kupfer (2014), que são classificados de acordo com os padrões de concorrência característicos de cada atividade industrial e são submetidos, de certa forma, aos mesmos fatores para os desempenhos de concorrência (KUPFER, 1998). Esta classificação é composta por quatro grupos industriais:

- Commodities agrícolas (CA): atividades intensivas em recursos naturais e energéticos, estando associadas geralmente ao agronegócio e a produtos homogêneos de alta tonelagem;

- Commodities industriais (CI): atividades intensivas em recursos naturais relacionadas com os setores da indústria extrativa mineral, metalurgia e química básica;

- Indústria tradicional (IT): indústria de bens com menor conteúdo tecnológico que produzem em unidades com poucos requisitos quanto à escala produtiva; produção de bens-salário, insumos, complementos industriais e bens de consumo manufaturados; é constituída por uma variedade de atividades, tais como produtos de metal, químicos diversos e material elétrico e, parte dedicada a manufatura de bens de consumo, como alimentos, têxtil, calçados e móveis, dentre outros;

- Indústria de bens com maior conteúdo tecnológico (IN): atividades mais sofisticadas na tecnologia e organização da produção adotada; é formada por setores que induzem o progresso técnico na economia, tais como produção de equipamentos mecânicos e eletrônicos e pelos setores de alta tecnologia e pela indústria de bens duráveis de consumo (automóveis, eletrônicos).

Diferentemente de outros estudos que analisam a indústria e optam por utilizar classificações baseadas em intensidade do conteúdo tecnológico da OECD (2003) ou de padrões setoriais de mudanças técnicas como em Pavitt (1984), essa classificação se baseia numa combinação entre fatores de demanda (e as categorias de uso, como bens de capital, intermediários, consumo durável e consumo não durável) e de oferta (sistemas técnicos de produção e fluxos tecnológicos). Além disso, em uma economia competitiva e aberta, o padrão de concorrência de um mercado é fundamental na determinação da competitividade das empresas que pertencem a cada grupo.

Apesar desse nível de apresentação para 19 atividades, todos os indicadores utilizados nesse estudo foram calculados para as 67 atividades, e só depois, foi realizada a devida agregação. A correspondência entre estes níveis de classificação está descrita no Apêndice B.

\footnotetext{
${ }^{5}$ Uma vez que houve mudanças metodológicas significativas entre o SCN 2000, no qual são publicadas as MIP 2000 e 2005 , e o SCN 2010, não se pode realizar uma comparação direta entre essas matrizes. É necessário algum processo de compatibilização entre tais SCN para uma análise temporal mais abrangente.

${ }^{6}$ Embora neste estudo seja apresentado apenas os dados para 2014, foram realizadas estimativas a partir da mesma metodologia para 2011 a 2013. Os interessados podem solicitar aos autores tais estimativas.
} 


\section{Breve panorama da estrutura produtiva da economia brasileira}

Analisando o comportamento VBP) ${ }^{7}$ entre 2010 e 2014, observamos um crescimento médio de $10,75 \%$ a. ${ }^{8}$. No Gráfico 1 podemos constatar que os setores de serviços foram os que mais cresceram no período, destacando-se Educação e saúde privada; Alojamento e alimentação e Atividades imobiliárias.

Gráfico 1 - Crescimento médio anual do valor bruto de produção para o Brasil, entre 2010 e 2014

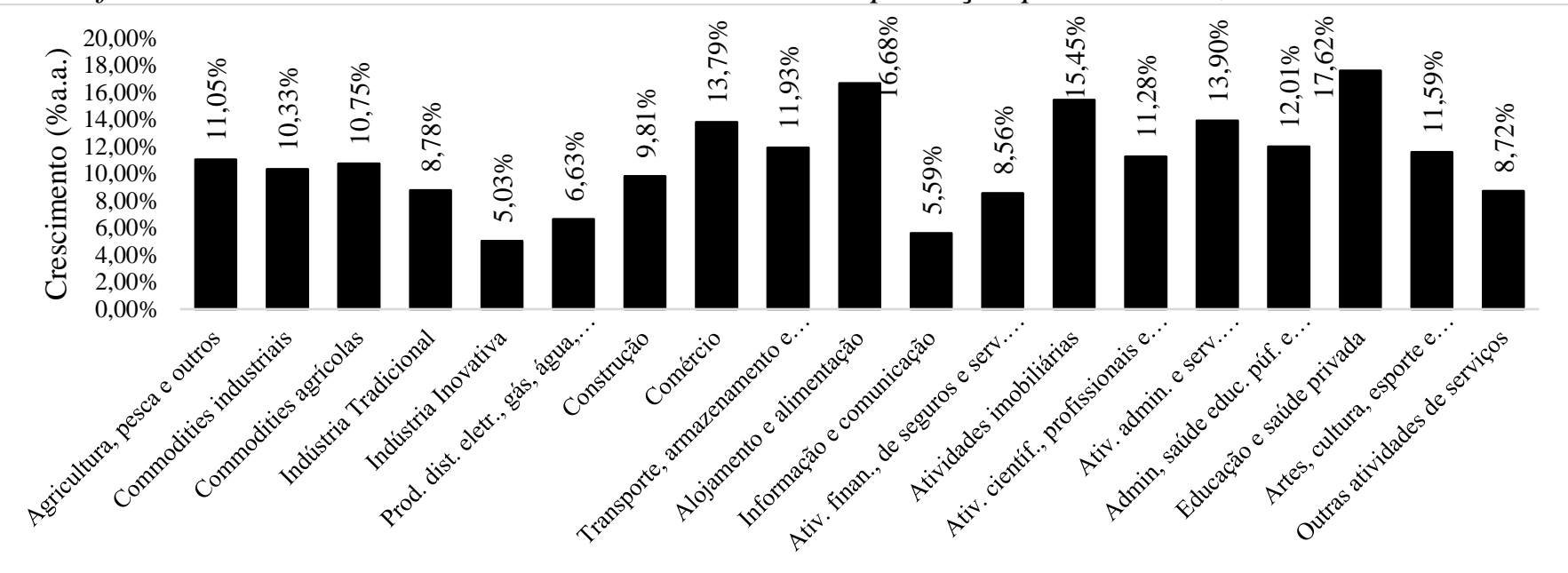

Fonte: Elaboração própria com base em IBGE (2016b) e estimativas realizadas nesse estudo.

Dentre as atividades industriais, a de Commodities agrícolas foi a que mais cresceu, sendo seguida das atividades Commodities Industriais, Indústria tradicional e Indústria inovativa. Este fato é preocupante, pois considerando a sofisticação tecnológica presente nesses grupos industriais, os que possuem maior intensidade são os que menos cresceram.

A composição setorial do VBP para 19 atividades (Gráfico 2), as cinco primeiras atividades a apresentarem as maiores proporções em relação ao VBP em 2010 são: Commodities industriais, Admin, saúde educ. púb. e segur.social, Comércio, Indústria tradicional e Indústria inovativa.

Gráfico 2 - Participação (\%) do VBP setorial no total da economia brasileira, 2010 e 2014, preços constantes relativos de 2010

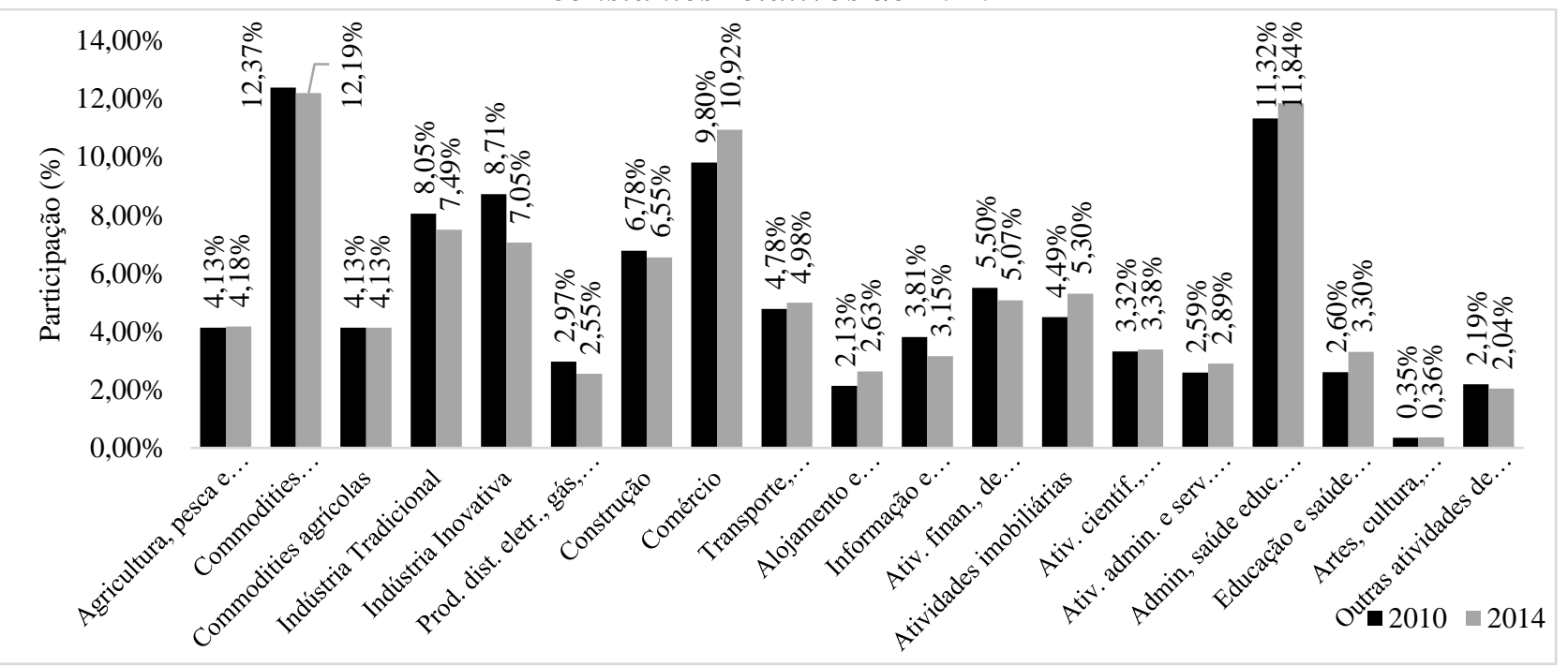

Fonte: Elaboração própria com base em IBGE (2016b) e estimativas realizadas nesse estudo.

\footnotetext{
${ }^{7}$ Os dados utilizados para fazer essa análise estão a preços constantes relativos de 2010. A série foi deflacionada pelos deflatores setoriais calculados a partir da Tabela de Recursos (IBGE, 2016b), a preços do ano corrente e a preços do ano anterior. Em seguida, foi encadeada criando a série a preços de 2010. Também foram corrigidos às variações dos preços relativos setoriais.

${ }^{8}$ Uma vez que tais informações estão dispostas a preços relativos constantes de 2010, essa variação representa variação em volume.
} 


\section{Análise de dados}

Nesta seção serão analisados os indicadores de poder de dispersão e sensibilidade de dispersão ${ }^{9}$, para as atividades da economia brasileira, em conjunto com a composição do encadeamento entre os setores $^{10}$, para os anos de 2010 e de 2014. De acordo com as combinações desses indicadores são possíveis 16 situações diferentes, como descrito nas Figuras 1, 2 e 3 para o VBP, VA e emprego.

Figura 1 - Quadro esquemático das atividades, segundo Poder de dispersão, Sensibilidade de dispersão e Grau de dispersão para valor bruto da produção, 2010 e 2014

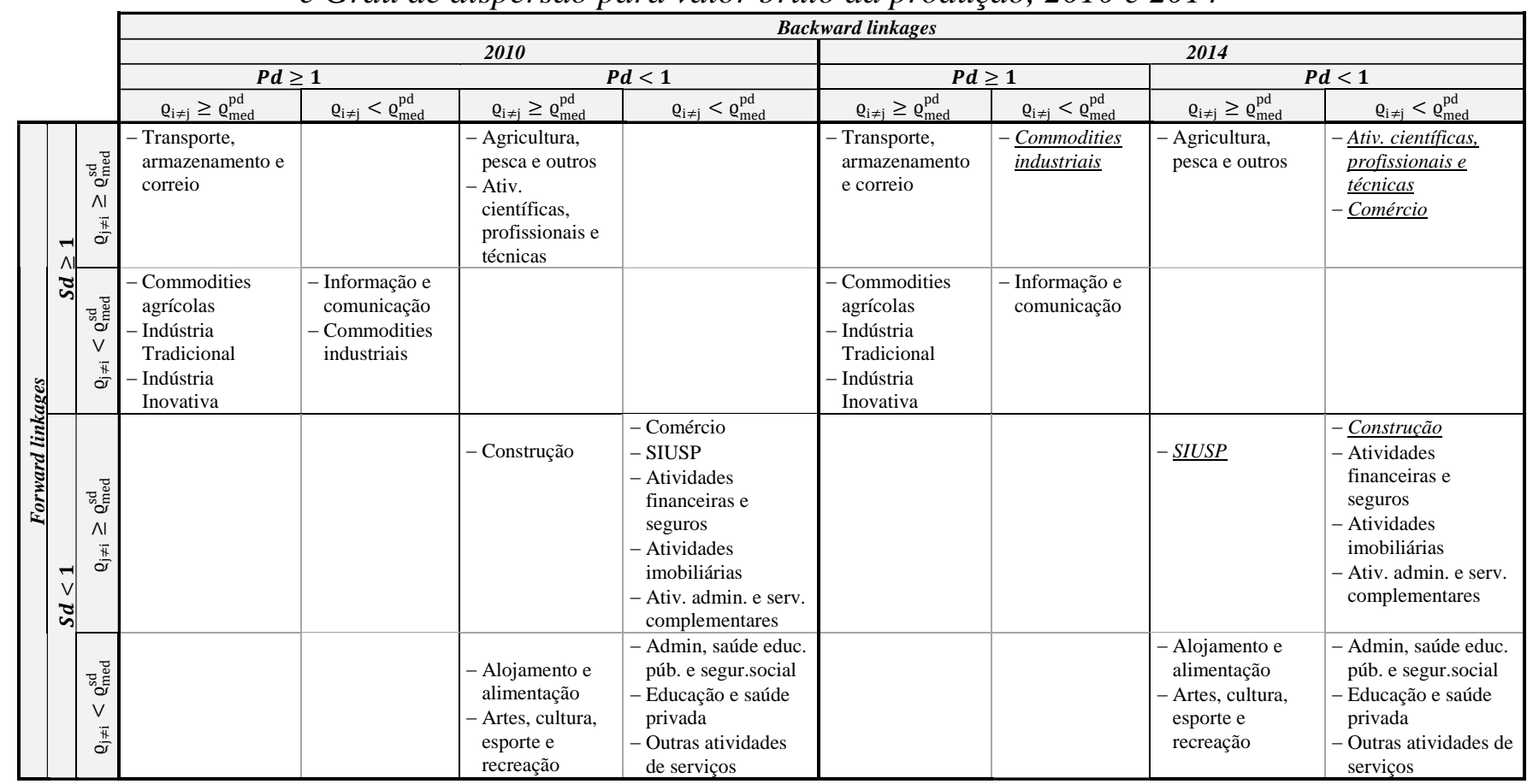

Fonte: Elaboração própria com base em IBGE (2016a, 2016b) e estimativas realizadas nesse estudo.

Para a produção, oito casos de combinações entre os indicadores mencionados são observados. Para o ano de 2010, seis atividades são consideradas chave, ou seja, apresentam $P d \geq 1$ e $S d \geq 1$ : Commodities industrias, Indústria tradicional, Indústria inovativa e Commodities agrícolas, Transporte, armazenamento e correio e Informação e comunicação. Desse grupo, destaca-se Transporte, armazenamento e correio com poder de arrastar a economia, gerado principalmente pelos outros setores, bem como sua sensibilidade em decorrência de um aumento uniforme da demanda. Assim, este setor, como era de se esperar, é dependente do comportamento extra setorial.

Os setores Indústria tradicional, Indústria inovativa e Commodities agrícolas, que são os setores que possuem da $2^{\mathrm{a}}$. a $4^{\mathrm{a}}$. posição com os maiores encadeamentos para trás, tem seu impacto extra setorial mais intenso nesse quesito. Assim, estes setores-chave possuem um efeito de arrasto da economia grande, no tocante a sua demanda de insumos intermediários. Entretanto, o impacto gerado pelo aumento da demanda, ou seja, a sensibilidade de dispersão nesses setores, tem efeitos mais acentuados para o próprio setor do que para o restante da economia.

Por último, dentre estes setores-chave, Commodities industriais (setor com maior $P d_{j}$ da economia) e Informação e comunicação possuem efeitos concentrados no seu setor tanto para o poder de dispersão ou sensibilidade de dispersão. Assim, apesar de seu poder de encadeamento para trás e para frente ser acima da média, seu impacto é em grande parte gerado para o próprio setor.

O próximo caso é composto das atividades que possuem $P d_{j}<1$ e $S d_{i} \geq 1$. Schuscnny (2005) chama os setores que apresentam esta combinação de indicadores de estratégicos, porque em casos de choques de demanda, são os que podem apresentar possíveis gargalos na economia. Os setores

\footnotetext{
${ }^{9}$ Os indicadores de poder de dispersão e sensibilidade de dispersão, juntamente com seu ordenamento, estão disponíveis na Tabelas 1 do Apêndice C.

${ }^{10}$ As proporções dos indicadores que são gerados no setor e nos demais setores, estão disponíveis na Tabela 2 do Apêndice C.
} 
pertencentes a este grupo são Agricultura, pesca e outros e Ativ. científicas, profissionais e técnicas. Assim, possuem baixo efeito de encadeamentos para trás, mas sua sensibilidade frente a um aumento na demanda é elevada e tais efeitos são sentidos pelos outros setores, uma vez que a proporção que é gerada nestes indicadores é maior do que para a média da economia.

O último caso gerado é daqueles setores que possuem tanto $P d_{j}$ quanto $S d_{i}$ menores do que a média da economia. Em geral estes setores utilizam uma quantidade pequena de insumos intermediários, dedicando-se prioritariamente a demanda final. São setores isolados, pois não provocam efeitos de arrasto elevado, e sua reação frente às variações de demanda é também pouco relevante, sendo em grande parte atividades de serviços.

Dentre estes, existem quatro subgrupos. O primeiro é constituído da atividade Construção, que possuí efeitos extra setorial maior do que a média da economia tanto para o $P d_{j}$ quanto para $S d_{i}$. Já as atividades Alojamento e alimentação e Artes, cultura, esporte e recreação tem seus efeitos de encadeamento para trás, apesar de baixo, distribuídos entre os setores. Os setores Comércio, SIUSP, Atividades financeiras e seguros, Atividades imobiliárias, Ativ. admin. e serv. complementares seus efeitos demanda de insumos intermediários baixos e, quando existentes, tendem a estar concentrados no próprio setor. Por último, as atividades de Admin, saúde educ. púb. e segur. social, Educação e saúde privada e Outras atividades de serviços possuem efeitos concentrados tanto para o $P d_{j}$ quanto $S d_{i}$, ou seja, grande parte dos seus efeitos são gerados ou influenciados pelo comportamento das suas próprias atividades.

Comparando 2010 com 2014, poucas mudanças ocorreram para a produção, estando destacadas na Figura 1, com as atividades que mudaram de posição (denotadas em itálico no ano de 2014). A média da composição dos encadeamentos tem uma pequena mudança a favor da concentração dos encadeamentos gerados na própria atividade. Para o $P d_{j}$, a proporção que é gerada dentro da atividade passa de $67,89 \%$ para $68,13 \%$ (diferença de 0,24 p.p.) e para $S d_{i}$, esta proporção se modifica de $65,43 \%$ para $66,33 \%$ (diferença de 0,9 p.p.).

Em geral, as atividades modicaram apenas sua posição em relação à média no tocante a distribuição dos efeitos gerados entre 2010 e 2014, permanecendo semelhante seus $P d_{j}$ e $S d_{i}$. Tais casos são Commodities industriais, que passa a ter seus efeitos de encadeamentos para frente melhor distribuídos entre os setores, o que tende a ser positivo para a economia por ser um setor-chave.

As atividades Ativ. científicas, profissionais e técnicas e Construção passaram a ter seus efeitos de backward linkages mais concentrados do que a média da economia. O contrário ocorreu com SIUSP que teve um aumento na proporção dos encadeamentos para trás que são atribuídos a outros setores. A única atividade que aumentou o $S d_{i}$ foi o Comércio, passando a ser considerado um setor estratégico, uma vez que tem grande importância no fornecimento de insumos a outros setores.

Na Figura 2 encontra-se a combinação dos indicadores analisados nessa seção para o valor adicionado. A grande maioria das atividades tem seu comportamento semelhante aos resultados obtidos para o valor bruto da produção em 2010 e 2014.

Em 2010, as oito atividades que possuem comportamento diferente, em geral é na composição do $P d_{j}$ e do valor da Sensibilidade de dispersão. As atividades Agricultura, pesca e outros, Ativ. científicas, profissionais e técnicas, Artes, cultura, esporte e recreação, que possuíam uma composição na geração de encadeamentos para trás melhor distribuída entre os setores na produção em comparação com a média da economia $\left(\varrho_{i \neq j} \geq \varrho_{\text {med }}^{\text {pd }}\right.$ ), passam a ter $P d_{j}$ que é gerado para próprio setor no valor adicionado maior do que a média da economia $\left(\rho_{\mathrm{i} \neq \mathrm{j}} \geq \rho_{\text {med }}^{\mathrm{pd}}\right)$. Comportamento contrário ocorre com as Commodities industriais e Informação e comunicação, que tinham o valor adicionado gerado pelo $P d_{j}$ mais concentrado no seu próprio setor, mas passa a ser mais distribuídos entre as atividades, quando comparado com a média da economia.

As atividades Commodities agrícolas, Ativ. admin. e serv. complementares e Comércio tem intensidades de $S d_{i}$ gerado pela produção e valor adicionado distintas em 2010. A primeira, que possuía $S d_{i}$ maior do que a média da economia no caso da produção, tem valor abaixo da média na geração do valor adicionado. Esse resultado é interessante, uma vez que indica que apesar da produção ter efeitos fortes na geração de encadeamentos para frente na produção, quando se analisa do ponto de vista da capacidade de geração valor adicionado, seu resultado é bem abaixo da média da economia. As atividades de serviços, Ativ. admin. e serv. complementares e Comércio, que para a produção possuem $S d<1$, para 
o VA tem $S d_{i}$ maior do que a média da economia, indicando a importância dos setores de serviços na geração de encadeamentos para a frente.

Figura 2 - Quadro esquemático das atividades, segundo Poder de dispersão, Sensibilidade de dispersão e composição dos encadeamentos para valor adicionado, 2010 e 2014

\begin{tabular}{|c|c|c|c|c|c|c|c|c|c|c|}
\hline & & & \multicolumn{8}{|c|}{ Backward linkages } \\
\hline & & & \multicolumn{4}{|c|}{2010} & \multicolumn{4}{|c|}{2014} \\
\hline & & & \multicolumn{2}{|c|}{$P d \geq 1$} & \multicolumn{2}{|c|}{$P d<1$} & \multicolumn{2}{|c|}{$P d \geq 1$} & \multicolumn{2}{|c|}{$P d<1$} \\
\hline & & & $\mathrm{Q}_{\mathrm{i} \neq \mathrm{j}} \geq \mathrm{e}_{\mathrm{med}}^{\mathrm{pd}}$ & $\mathrm{\varrho}_{\mathrm{i} \neq \mathrm{j}}<\mathrm{e}_{\text {med }}^{\mathrm{pd}}$ & $\mathrm{Q}_{\mathrm{i} \neq \mathrm{j}} \geq \mathrm{Q}_{\text {med }}^{\mathrm{pd}}$ & $\mathrm{Q}_{\mathrm{i} \neq \mathrm{j}}<\mathrm{e}_{\mathrm{med}}^{\mathrm{pd}}$ & $\varrho_{i \neq j} \geq \varrho_{\text {med }}^{p d}$ & $\mathrm{Q}_{\mathrm{i} \neq \mathrm{j}}<\mathrm{e}_{\mathrm{med}}^{\mathrm{pd}}$ & $\varrho_{i \neq j} \geq \varrho_{m e d}^{p d}$ & $\mathrm{Q}_{\mathrm{i} \neq \mathrm{j}}<\mathrm{e}_{\text {med }}^{\mathrm{pd}}$ \\
\hline & 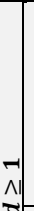 & 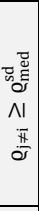 & $\begin{array}{l}\text { - Transporte, } \\
\text { armazenamento e } \\
\text { correio }\end{array}$ & & & $\begin{array}{l}\text { - Comércio* } \\
\text { - Agricultura, pesca e } \\
\text { outros* } \\
\text { - Ativ. científicas, } \\
\text { profissionais e } \\
\text { técnicas* } \\
\text { - Ativ. admin. e serv. } \\
\text { Complementares* }\end{array}$ & $\begin{array}{l}\text { - Transporte, } \\
\text { armazenamento e } \\
\text { correio }\end{array}$ & & & $\begin{array}{l}\text { - Comércio } \\
\text { - Agricultura, pesca e } \\
\text { outros* } \\
\text { - Ativ. científicas, } \\
\text { profissionais e } \\
\text { técnicas } \\
\text { - Ativ. admin. e serv. } \\
\text { Complementares* }\end{array}$ \\
\hline $\begin{array}{c}5 \\
3 \\
3 \\
3 \\
3 \\
3 \\
3\end{array}$ & है & 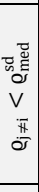 & $\begin{array}{l}\text { - Commodities } \\
\text { industriais* } \\
\text { - Indústria } \\
\text { Tradicional } \\
\text { - Indústria Inovativa } \\
\text { - Informação e } \\
\text { comunicação* } \\
\end{array}$ & & & & $\begin{array}{l}\text { - Commodities } \\
\text { industriais* } \\
\text { - Indústria } \\
\text { Tradicional } \\
\text { - Indústria Inovativa } \\
\text { - Informação e } \\
\text { comunicação* } \\
\end{array}$ & & & \\
\hline 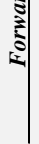 & & 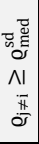 & & & - Construção & $\begin{array}{l}\text { - SIUSP } \\
\text { - Ativ. finan., de } \\
\text { seguros e serv. relac... } \\
\text { - Atividades } \\
\text { imobiliárias }\end{array}$ & & & $\begin{array}{l}\text { - Construção* } \\
\text { - } \underline{\text { SIUSP }}\end{array}$ & $\begin{array}{l}\text { - Ativ. finan., de } \\
\text { seguros e serv. relac... } \\
\text { - Atividades } \\
\text { imobiliárias } \\
\text { - Construção }\end{array}$ \\
\hline & के & 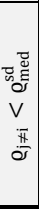 & $\begin{array}{l}\text { - Commodities } \\
\text { agrícolas* }\end{array}$ & & $\begin{array}{l}\text { - Alojamento e } \\
\text { alimentação }\end{array}$ & $\begin{array}{l}\text { - Admin, saúde educ. } \\
\text { púb. e segur.social } \\
\text { - Educação e saúde } \\
\text { privada } \\
\text { - Artes, cultura, esporte } \\
\text { e recreação* } \\
\text { - Outras atividades de } \\
\text { serviços }\end{array}$ & $\begin{array}{l}\text { - Commodities } \\
\text { agrícolas* }\end{array}$ & $-\frac{\text { Admin, saúde }}{\text { educ.púb.e }}$ & $\begin{array}{l}\text { - Alojamento e } \\
\text { alimentação } \\
-\frac{\text { Artes, cultura, }}{\text { esporte e }} \\
\text { recreação }\end{array}$ & $\begin{array}{l}\text { - Educação e saúde } \\
\text { privada } \\
\text { - Outras atividades de } \\
\text { serviços }\end{array}$ \\
\hline
\end{tabular}

Fonte: Elaboração própria com base em IBGE (2016a, 2016b) e estimativas realizadas nesse estudo.

Obs: As atividades marcadas com (*) indicam que estas se modificam, quando comparadas com a posição obtida com o VBP (Figura 1)

Comparando os encadeamentos de 2010 e 2014 para o valor adicionado, $\varrho_{\text {med }}^{\text {pd }}$ é respectivamente $36,63 \%$ e 36,40\%, indicando uma pequena queda de 0,23p.p dos indicadores que são gerados fora do setor, em comparação com os dois anos. Cinco são as atividades-chave para o valor adicionado: Commodities industrias, Indústria tradicional, Indústria inovativa e Transporte, armazenamento $e$ correio e Informação e comunicação.

Apenas duas atividades modificaram suas posições em 2014 quando comparadas com 2010. As atividades SIUSP e Artes, cultura, esportes e recreação, que tinham a composição de seus setores concentrados neles mesmo, passam a ter tais indicadores dispersos para o poder de dispersão, mas permanecendo com $P d<1$.

$\mathrm{Na}$ Figura 3 encontram-se a combinação dos indicadores analisados para o emprego. O comportamento das atividades não se modifica nos anos de 2010 e 2014, indicando não haver mudança quando comparada a estrutura entre as atividades do ponto de vista do emprego. Em comparação com o valor bruto de produção, apenas três atividades possuem as mesmas combinações (Indústria tradicional, Admin, saúde educ. púb. e segur. social e Educação e saúde privada. Já comparando as possibilidades do emprego com as do valor adicionado, cinco atividades permanecem semelhantes (Commodities agrícolas, Indústria tradicional, Comércio, Ativ. admin. e serv. complementares e Educação e saúde privada).

As atividades-chave, para o emprego, ou seja, aquelas que apresentam $P d \geq 1$ e $S d \geq 1$ são a Indústria tradicional, Outras atividades de serviços e Agriculture, fishing and other, mas a dispersão existente na geração dos encadeamentos é diferente entre elas. É interessante analisar que dentre estas atividades, somente a Indústria Tradicional é também uma atividade-chave relacionada à produção e ao valor adicionado. Esta apresenta elevado multiplicador de emprego para trás e tem impacto maior do que a média na geração de empregos para outros setores. Do ponto de vista do Sd, os empregos gerados são em grande parte no próprio setor. Este fato é esperado, uma vez que como essa atividade é a agregação de outras atividades industriais, tem como característica a provisão de insumos que são utilizados na produção intraindustrial de bens. 
Figura 3 - Quadro esquemático das atividades, segundo Poder de dispersão, Sensibilidade de dispersão

\begin{tabular}{|c|c|c|c|c|c|c|}
\hline & & & e Grau de $d$ & e ersão para empr & $\frac{e g o, 2010 \text { e } 2014^{11}}{\text { Backward linkages }}$ & \\
\hline & & & \multicolumn{4}{|c|}{2010 e 2014} \\
\hline & & & \multicolumn{2}{|c|}{$P d \geq 1$} & \multicolumn{2}{|c|}{$P d<1$} \\
\hline & & & $\varrho_{i \neq j} \geq \varrho_{\text {med }}^{p d}$ & $\mathrm{Q}_{\mathrm{i} \neq \mathrm{j}}<\mathrm{Q}_{\text {med }}^{\mathrm{pd}}$ & $\varrho_{i \neq j} \geq \varrho_{m e d}^{p d}$ & $\mathrm{\varrho}_{\mathrm{i} \neq \mathrm{j}}<\mathrm{e}_{\text {med }}^{\mathrm{pd}}$ \\
\hline \multirow{4}{*}{$\begin{array}{l}\text { Forward } \\
\text { linkages }\end{array}$} & \multirow[t]{2}{*}{$S d \geq 1$} & $\varrho_{j \neq i} \geq \varrho_{\text {med }}^{\text {sd }}$ & & - Agricultura, pesca e outros & & $\begin{array}{l}\text { - Comércio } \\
\text { - Transporte, armazenamento e correio } \\
\text { - Ativ. admin. e serv. complementares }\end{array}$ \\
\hline & & $\varrho_{j \neq i}<\varrho_{\text {med }}^{\text {sd }}$ & - Indústria Tradicional & - Outras atividades de serviços & & \\
\hline & \multirow[b]{2}{*}{$S d<1$} & $\varrho_{j \neq i} \geq \varrho_{\text {med }}^{\text {sd }}$ & & & $\begin{array}{l}\text { - Ativ. finan., de seguros e serv. relac... } \\
\text { - Atividades imobiliárias }\end{array}$ & - Ativ. científicas, profissionais e técnicas \\
\hline & & $\varrho_{j \neq i}<\varrho_{\text {med }}^{\text {sd }}$ & $\begin{array}{l}\text { - Commodities industriais } \\
\text { - Commodities agrícolas } \\
\text { - Indústria Inovativa }\end{array}$ & & $\begin{array}{l}\text { - SIUSP } \\
\text { - Construção } \\
\text { - Informação e comunicação }\end{array}$ & $\begin{array}{l}\text { - Alojamento e alimentação } \\
\text { - Admin, saúde educ. púb. e segur.social } \\
\text { - Educação e saúde privada } \\
\text { - Artes, cultura, esporte e recreação }\end{array}$ \\
\hline
\end{tabular}

Fonte: Elaboração própria com base em IBGE $(2016 a, 2016 b)$ e estimativas realizadas nesse estudo.

A predominância da atividade Outras atividades de serviços e Agriculture, fishing and other como atividades-chave (ocupando a $2^{\mathrm{a}}$ e $3^{\mathrm{a}}$ posição no ordenamento do $P d_{j}$ para emprego contra a $14^{\mathrm{a}}$ e $8^{\mathrm{a}}$ posição para a produção, em 2010) demonstram uma elevada proporção de empregos que são geradas nessas atividades. Para a atividade Outras atividades de serviços, apesar do elevado encadeamento, quase a totalidade dos empregos gerados, tanto pelo $P d_{j}$ quanto $S d_{i}$, são concentrados na própria atividade, tendo poucos efeitos de arrasto nos demais setores. Já os empregos que seriam gerados via encadeamentos para trás pela expansão de uma unidade de produto na atividade Agriculture, fishing and other, são quase na sua totalidade (cerca de $90 \%$ ) destinados à própria atividade. Por outro lado, efeitos dos encadeamentos para frente são mais dispersos entre as atividades, o que é de se esperar pela natureza de fornecedora de insumos dessa atividade.

As atividades Commodities Industriais, Commodities agrícolas e Indústria Inovativa apresentam o poder de dispersão para emprego maior do que um, indicando um efeito de arrasto na geração de empregos para trás elevado e também com efeitos difundido para as demais atividades, característica das atividades industriais. Já os efeitos gerados pelos encadeamentos para frente são menores do que a média da economia $\left(S d_{i}<1\right)$, bem como estes efeitos são concentrados nessas atividades.

As atividades Comércio, Transporte, armazenamento e correio e Ativ. admin e serv. complementares, possuem os multiplicadores de encadeamentos para trás menores do que a média da economia, mas por outro lado tem grande importância na geração de empregos derivado dos encadeamentos para frente, sendo maior do que a média da economia.

As demais atividades, em geral de serviços, apresentam $P d$ e $S d$ menores do que a média da economia. Modifica-se apenas a composição dos encadeamentos entre os setores, sendo algumas mais concentradas no setor e outras nas demais atividades.

\section{Comentários finais}

De maneira geral, os indicadores de encadeamentos apresentados aqui para a produção revelam importância acentuada das atividades industriais, tendo duas atividades de serviço (Transporte, armazenagem e correio e Informação e comunicação) como atividade-chave. No caso dos indicadores calculados para o valor adicionado, os encadeamentos e sua composição é muito próxima aos casos observados para o valor bruto da produção. Já para os indicadores de emprego, atividades industriais são importantes, em especial a Indústria Tradicional, mas outras como agropecuária e serviços aparecem com maior importância. Somente a Indústria Tradicional é também uma atividade-chave relacionada VBP, emprego e VA.

\footnotetext{
${ }^{11}$ A atividade Ativ. científicas, profissionais e técnicas, tem-se que $\varrho_{\mathrm{i} \neq \mathrm{j}}<\mathrm{Q}_{\mathrm{med}}^{\mathrm{pd}}$, indicando que Pd estaria concentrada na própria atividade, quando comparada à média da economia. Já quando comparado o coeficiente de variação $(C V)$ em relação ao médio da economia, tem-se que $\left(C V_{j}<C V_{\text {med }}\right)$. Seguindo o mesmo critério de comparação em relação à média, indicaria que a distribuição os dados dessa atividade seria mais homogênea (ou melhor distribuída) em comparação com o $C V$ médio da economia. $\mathrm{O}$ mesmo ocorre para a atividade SIUSP, só que para o $S d$.
} 
A atividade que gera o maior encadeamento para a produção e valor adicionado são Commodities Industriais, tendo caráter extrativa, rica em recursos naturais. Para a produção, esta atividade gera altos, mas seus efeitos para frente e para trás são concentrados na própria atividade. Para o caso do emprego a atividade que possui maior encadeamento é a Indústria tradicional, que possui baixo conteúdo tecnológico, com poucos requisitos de escala de produção, sendo caracterizado por bens salários.

A Indústria inovativa, que possui maior conteúdo tecnológico e é indutora do progresso técnico na economia, ocupa em geral apenas a terceira posição nos encadeamentos, ficando apenas à frente das Commodities agrícolas. Além disso, a Indústria inovativa foi a que mais perdeu participação do seu VBP no total da economia. Pensando em uma estratégia de desenvolvimento de longo prazo, o potencial de indução dessa atividade para a economia é limitado.

A despeito do debate sobre a existência ou não de um processo de desindustrialização na economia brasileira, a indústria continua sendo importante para a geração de encadeamentos, sendo os principais setores-chave na economia, entre 2010 e 2014, principalmente analisando os indicadores de VA e VBP.

Pela análise realizada nesse estudo, a estrutura da economia brasileira permanece semelhante entre 2010 e 2014, analisada sobre o prisma proposto neste estudo. Houve, entretanto, uma tímida mudança na esquematização das atividades para o VBP e VA, permanecendo semelhante no emprego. Apesar de que a estimação de MIPs ser um procedimento amplamente utilizado para obter uma estrutura completa da matriz insumo-produto para MIPs de anos não divulgados, parte desse resultado da semelhança da estrutura entre 2010 e 2014 pode ser decorrente da forma de atualização das MIP utilizadas nesse trabalho.

A semelhança na estrutura da economia entre 2010 e 2014 contrasta com o observado em Morrone (2016), em que alguns setores mudam suas posições no encadeamento de maneira mais acentuada do que observada nesse estudo. É necessário, entretanto, qualificar essa comparação, principalmente porque são utilizados níveis de agregações diferentes e indicadores de encadeamento distintos. Outro fator que pode influenciar essa análise é a diferença nos métodos de atualização, uma vez que este autor utiliza a metodologia proposta por Guilhoto e Sesso (2005, 2010).

Destaca-se nesse estudo a importância em realizar uma análise multissetorial da estrutura da economia brasileira. A análise dos indicadores dos encadeamentos em conjunto com sua decomposição permite identificar não apenas o ordenamento dos encadeamentos, dado pelos valores o poder de dispersão e sensibilidade de dispersão, mas também fornece base para analisar a interação dos setores com os demais setores da economia.

\section{Referências}

BASTOS, Carlos Pinkusfeld; RODRIGUES, Roberto de Souza; LARA, Fernando Maccari. As finanças públicas e o impacto fiscal entre 2003 e 2012: 10 anos de governo do Partido dos Trabalhadores. Ensaios FEE, v. 36, n. 3, p. 675-706, 2015.

BOUCHER, Michel. Some further results on the linkage hypothesis. The Quarterly Journal of Economics, $p$. 313-318, 1976.

CHENERY, Hollis B.; TAYLOR, Lance. Development patterns: among countries and over time. The Review of Economics and Statistics, p. 391-416, 1968.

CLARK, Colin. The Conditions of Economic Progress, London 1940.The Conditions of Economic Progress, 1940.

DIETZENBACHER, Erik. The measurement of interindustry linkages: key sectors in the Netherlands. Economic Modelling, v. 9, n. 4, p. 419-437, 1992.

DIETZENBACHER, E.; LOS, B. Structural decomposition techniques: Sense and sensitivity. Economic Systems Research, v. 10, n. 4, p. 307-324, 1998.

FEIJÓ, Carmem Aparecida; RAMOS, Roberto Luis Olinto. Contabilidade social: a nova referência das contas nacionais do Brasil. rev. e atual. Rio de Janeiro: Campus, 2008. 
FISHER, Allan GB. Production, primary, secondary and tertiary. Economic Record, v. 15, n. 1, p. 24-38, 1939.

FREITAS, F.N.P.; DWECK, E. The Pattern of Economic Growth of the Brazilian Economy 1970-2005. In: E.S. Levrero, A. Palumbo, and A. Stirati (eds.) Sraffa and the Reconstruction of Economic Theory: Volume Two. Basingstoke, Palgrave Macmillan, 158-192. 2009

GRIJÓ, E. BÊRNI, D.A. Metodologia completa para a estimativa de matrizes de insumo-produto. Teoria e evidência econômica, Passo fundo, v. 14, n. 26, p.9-42, maio 2006. Disponível em: <http://www.upf.br/cepeac/download/rev_n26_2006_art1.pdf? origin=publication_detail> Acesso em: 20 jul. 2014.

GUILHOTO, J.J.M. E U. SESSO FILHO. Estimação da Matriz Insumo-Produto a Partir de Dados Preliminares das Contas Nacionais. Economia Aplicada. Vol. 9. N. 2. Abril-Junho. pp. 277-299, 2005.

GUILHOTO, J.J.M., U.A. SESSO FILHO. Estimação da Matriz Insumo-Produto Utilizando Dados Preliminares das Contas Nacionais: Aplicação e Análise de Indicadores Econômicos para o Brasil em 2005. Economia \& Tecnologia. UFPR/TECPAR. Ano 6, Vol 23, Out./Dez 2010.

RASMUSSEN, Poul Nørregaard. Studies in inter-sectoral relations. E. Harck, 1956.

GÜNLÜK-ŞENESEN, G.; BATES, John M. Some experiments with methods of adjusting unbalanced data matrices. Journal of the Royal Statistical Society. Series A (Statistics in Society), p. 473-490, 1988.

HIRSCHMAN, Albert O. The strategy of economic development. New Haven: yale university Press, 1958.

IBGE. Matriz insumo-produto Brasil: 2000-2005. Contas nacionais, n.23, IBGE: Rio de Janeiro, 2008. Disponível em: 〈http://www.ibge.gov.br/home/estatistica/economia/ matrizinsumo_produto/publicacao.pdf>. Acesso em: 05 abr. 2014.

Sistema de contas nacionais: Brasil, ano de referência 2010. Séries Relatórios Metodológicos, v. 24. Coordenação de Contas Nacionais/IBGE. 3. ed. - Rio de Janeiro, 2016a. Disponível em: <http://biblioteca.ibge.gov.br/visualizacao/livros/liv98142.pdf>. Acesso em: 30 set 2016.

Matriz de insumo-produto: Brasil 2010. IBGE, Rio de Janeiro, 2016b. Disponível em: <http://biblioteca.ibge.gov.br/visualizacao/livros/liv98180.pdf >. Acesso em: 11 nov. 2016.

JUNIUS, Theo; OOSTERHAVEN, Jan. The solution of updating or regionalizing a matrix with both positive and negative entries. Economic Systems Research, v. 15, n. 1, p. 87-96, 2003.

KUPFER, David. Um referencial para a análise da reestruturação da Indústria brasileira. In: Trajetórias de reestruturação da indústria brasileira após a abertura e a estabilização. 1998. Tese (Doutorado) - Curso de Economia, Instituto de Economia, Universidade Federal do Rio de Janeiro, Rio de Janeiro, 1998. Cap. 3.

A indústria brasileira após a abertura. In CASTRO, A. C.; LICHA, A. PINTO JR. H. Q.; SABÓIA, J. Brasil em Desenvolvimento: Economia, Tecnologia e Competitividade. Vol 1. Parte III. Rio de Janeiro. Ed. Civilização Brasileira, 2005.

KUZNETS, Simon. On comparative study of economic structure and growth of nations. In: The Comparative Study of Economic Growth and Structure. NBER, 1959. p. 162-176.

LEITE, F. P. Elementos de Teoria da Produção e Análise Insumo-Produto. 2017. Mimeo.

LEONTIEF, W. The Structure of American Economy, 1919-1939, New York, Sharpe. 1940.

Studies in the Structure of the American Economy. New York: Oxford University Press, 1953.

LEWIS, W. Arthur. Economic development with unlimited supplies of labour.Themanchester school, v. 22, n. 2, p. 139-191, 1954. 
MARTINEZ, Thiago Sevilhano. Método RAWS/RAW para estimação anual da Matriz de Insumo-Produto na referência 2000 das Contas Nacionais. Texto para Discussão, Instituto de Pesquisa Econômica Aplicada (IPEA), 2015.

MILLER, R. E.; BLAIR, P. D. Input-output analysis: foundations and extensions. Cambridge University Press, 2009.

MORCEIRO, Paulo César. Desindustrialização na economia brasileira no período 2000-2011: abordagens e indicadores. Coleção PROPG Digital (UNESP), p. 301 p.: il., gráfs., tabs., 2012.

MORRONE, H. Which sectors to stimulate first in Brazil? Estimating the sectoral power to pull the economy out of the recession. In: Anais eletrônicos.... Encontro Nacional de Economia, 43, Foz do Iguaçu, ANPEC, 2016. Disponível em: <https://goo.gl/jtmyBL>. Acesso em: 20 dez. 2016.

NASSIF, Luiza; TEIXEIRA, Lucas; ROCHA, Frederico. Houve redução do impacto da indústria na economia brasileira no período 1996-2009? Uma análise das matrizes insumo-produto. Economia e Sociedade, v. 24, n. 2, p. 355-378, 2015.

ORGANISATION FOR ECONOMIC CO-OPERATION AND DEVELOPMENT, OECD. A Proposed Classification of ICT Goods. OECD Working Party on Indicators for the Information Society, Paris, 2003.

PAVITT, Keith. Sectoral patterns of technical change: towards a taxonomy and a theory. Research policy, v. 13, n. 6, p. 343-373, 1984.

RASMUSSEN, Poul Nørregaard. Studies in inter-sectoral relations. E. Harck, 1956.

ROSTOW, Walt Whitman. The process of economic growth. 1960.

ROWTHORN, R.; WELLS, John R. De-Industrialization Foreign Trade. CUP Archive, 1987.

SCHUSCHNY, Andrés Ricardo. Tópicos sobre el modelo de insumo-producto: teoría y aplicaciones. Serie Estudios estadísticos y prospectivos, 37, División de Estadística y Proyecciones Económicas/CEPAL/United Nations Publications, Santiago de Chile, dic. 2005. Disponível em: 〈https://goo.gl/QC0ZJu〉. Acesso em 15 dez. 2016.

SUMMA, Ricardo; SERRANO, Franklin. Distribution and Cost-Push inflation in Brazil under inflation targeting, 1999-2014. Mimeo, 2015. Disponível em: <http://www.excedente.org/wpcontent/uploads/2015/11/summa-serrano-1-oct-2015-Distribution-and-Cost-Push-inflation-in-Brazil-underinflation-targeting-1999-2014-.pdf>. Acesso em: 09 dez 2015.

SYRQUIN, Moshe. Patterns of structural change. Handbook of development economics, v. 1, p. 203-273, 1988.

TEMURSHOEV, Umed; MILLER, Ronald E.; BOUWMEESTER, Maaike C. A note on the GRAS method. Economic Systems Research, v. 25, n. 3, p. 361-367, 2013.

TONER, Phillip. Main currents in cumulative causation: the dynamics of growth and development. Macmillan, 1999.

TORRACCA, Julia Ferreira; KUPFER, David . A evolução da taxa de câmbio efetiva real setorial e a mudança estrutural no padrão de comércio da indústria brasileira. In: Anais eletrônicos.... Encontro Nacional de Economia, 41, Natal, ANPEC. 2014. Disponível em: < https://goo.gl/f9Unig>. Acesso em: 15 jan. 2017. 


\section{Apêndice A}

Neste estudo, a estimação da MIP de 2014 a partir das TRUs deste mesmo ano segue a metodologia proposta por Grijó e Berni (2006). Esta última utiliza informações estruturais presentes na Matriz insumo-produto (MIP) de 2010, que são utilizadas para estimar a MIP $2014^{12}$, com base nas Tabelas de Recursos e Usos (TRUs) deste mesmo ano. A seguir serão apresentados alguns procedimentos necessários preliminares para a elaboração da estimativa.

\section{A.1. Preparação dos dados}

\section{- Nível de agregação}

A MIP 2010 é divulgada na sua maior classificação no nível 67 atividades e 127 produtos. Entretanto, as TRUs são divulgadas no nível de classificação é 68 atividades e 128 produtos. Para compatibilizar as duas bases e seguindo a classificação da CNAE 2.0, foram agregados nas TRU os produtos Comércio e reparação de veículos e Comércio por atacado e a varejo, exceto veículos automotores, no produto Comércio por atacado e varejo.

Para as atividades, agregaram-se os dados de Comércio e reparação de veículos automotores e motocicletas e Comércio por atacado e a varejo, exceto veículos automotores, na atividade Comércio por atacado e varejo.

Tendo em vista a forma como o ajuste CIF/FOB é realizado pelo IBGE (2016), optou-se por agregar todos os produtos de transporte, nas MIPs e TRUs. Tais produtos são: Transporte terrestre de carga, Transporte terrestre de passageiros, Transporte aquaviário, Transporte aéreo, Armazenamento e serviços auxiliares aos transportes. Tal agregação é denominada "Transporte, armazenamento e serviços auxiliares aos transportes". Nos dados das importações, a parte referente aos fretes, é denotada com valores negativos. Para que o total das importações nesses produtos (importação dos bens e serviços mais ajuste CIF/FOB) tivesse um valor positivo, preferiu-se a agregação desses produtos.

A partir das agregações realizadas os dados das TRUs de 2014 e das MIPs de 2010 passam a ter nível de detalhamento máximo de 67 atividades e 123 produtos.

\section{- Ajuste CIF-FOB: diferença entre TRU e MIP}

Pela informação que consta no manual da Matriz Insumo-Produto 2010 (IBGE 2016), há diferença no valor da oferta importada de transporte e seguros em relação ao valor presente na TRU 2010, devido ao ajuste CIF (Cost, Insurance and Freight)-FOB (Free on Board).

Esse ajuste é necessário para que não haja dupla contagem, pois os produtos importados são valorados incluindo a parcela de frete e seguros (CIF); porém, tais serviços também estão contidos na oferta, seja na forma de importação ou produção.

Nas TRU 2010 essa parcela de ajuste foi considerada integralmente como uma importação negativa. Entretanto, o IBGE (2016) segue a recomendação do manual do System of national accounts 2008 (doravante, SNA 2008) na MIP e considera como exportação a parcela que corresponde aos produtores nacionais. Assim, o total das importações e importações para os serviços de transportes na MIP 2010 é maior do que o obtido na TRU. O saldo por produto desses dados não são afetados, entretanto há uma modificação na composição entre as exportações e importações.

Dado este problema, foi realizado um ajuste prévio das TRUs, introduzindo a modificação sugerida pelos SNA 2008, para adequar os dados das TRUs aos dados das MIPs, para o produto (agregado) "Transporte, armazenamento e serviços auxiliares aos transportes".

Primeiramente, foi realizada a diferença entre os dados das importações das TRUs 2010 e da MIP 2010 e em seguida, foi calculada a proporção entre essa diferença e o dado do valor do ajuste CIF-FOB, presente na MIP 2010. A proporção calculada para o ano de 2010 é de 0,7079 . Esta foi aplicada ao ano de 2014. Ao multiplicar valor do ajuste CIF-FOB de cada ano, encontra-se o novo valor de importações negativas e o restante é atribuído positivamente às exportações.

Uma vez feitos estes ajustes, para esse produto, foram calculados novos totais nas TRUs. A primeira preparação na Tabela de Recursos é na parte de importações, em que o novo valor estimado para o ajuste CIF-FOB substitui o valor divulgado pelo IBGE nas TRUs de 2011 à 2014. Na Tabela dos Recursos, pela alteração das importações, necessitou-se recalcular os valores da Oferta Total a Preços Básicos (produção nacional adicionada ao novo valor das importações, considerando o ajuste CIF-FOB) e da Oferta Total a Preços do Consumidor (Oferta Total a Preços Básicos mais margem de comércio, margem transporte e impostos líquidos de subsídios).

\footnotetext{
${ }^{12}$ Embora neste estudo seja apresentado apenas os dados para 2014, foram realizadas estimativas a partir da mesma metodologia para 2011 a 2013. Os interessados podem solicitar aos autores tais estimativas.
} 
Na tabela de Usos é adicionado ao vetor de exportações o negativo resultante da diferença da do ajuste CIFFOB efetivo (divulgado pelo IBGE) com o calculado pelo ajuste. Assim, recalcula-se o novo valor para Demanda Final e Demanda Total.

Para o ano de 2014, a informação das importações presente nas TRUs são líquidas do ajuste CIF-FOB, não contendo o valor em separado. Sem essa informação, não é possível fazer a realocação entre importações (negativas) e exportações (positiva). Portanto, foi realizada uma estimativa para realizar este ajuste a partir das proporções do último ano, 2013. Tal estimativa foi realizada para os dados de transporte desagregados (em grande maioria incidente do ajuste CIF-FOB). Calcula-se a proporção do ajuste CIF-FOB em relação ao total das importações para os produtos em 2013 e em seguida estima-se a proporção de ajuste CIF-FOB para 2014. Com esta última é possível calcularmos o ajuste CIF-FOB para este ano e assim procedermos com ajuste apresentado acima.

\section{A.2. O método de atualização}

Nesta subseção será apresentado brevemente o método utilizado por Grijó e Berni (2006). Este método consiste na utilização de informações estruturais presentes em uma matriz insumo-produto para um ano cuja base tenha sido divulgada oficialmente.

\section{- Primeiro passo: gerando informações estruturais (mark-downs)}

As tabelas de recursos e usos da produção são formadas por duas partes: a Tabela de Recursos dos Bens e Serviços, que demonstra as condições da oferta dos produtos, e a Tabela de Usos dos Bens e Serviços, em que são ditas as condições das suas demandas. Tais tabelas são construídas a partir do princípio de equilíbrio entre oferta e demanda de mercado, o qual o valor da oferta total a preços do consumidor é igual à demanda total, por produto. Assim, tais vetores são equivalentes, uma vez que o valor total da oferta de cada produto é igual ao valor observado na demanda.

As informações nas TRUs são divulgadas a preços do consumidor, enquanto as informações das MIP estão disponíveis a preços básicos. As informações que são valoradas em preços do consumidor estão relacionadas ao preço final do bem ou serviço que o consumidor pagou para obtê-la, ou seja, "dentro da loja". Logo, além do preço da mercadoria em si, incluem-se os impostos pagos sobre os produtos (líquidos de subsídios), o valor do transporte da mercadoria do setor produtivo até a entrega ao consumidor e o serviço de comércio no varejo e atacado.

Quando uma informação está valorada a preços básicos, considera o preço que é recebido pelo produtor pela venda de uma mercadoria, ou seja, "na porta da fábrica". Além disso, o interesse nessas informações é a produção nacional, também se deduz as informações da parcela da oferta que é atendida por bens importados.

A partir disso, é possível estabelecer uma relação entre o fluxo oferta total das atividades/produtos a preços de consumidor $\left(\mathbf{A}^{\mathbf{p c}}=\left[\mathrm{a}_{\mathrm{ij}}^{\mathrm{pc}}\right]\right)$, formado a partir da oferta nacional a preços básicos $\left(\mathbf{A}^{\mathbf{p b}}=\left[\mathrm{a}_{\mathrm{ij}}^{\mathrm{pc}}\right]\right)$, mais o valor das margens de comércio $\left(\mathbf{M C}=\left[\mathrm{mc}_{\mathrm{ij}}\right]\right)$ e transporte $\left(\mathbf{M T}=\left[\mathrm{mt}_{\mathrm{ij}}\right]\right)$, dos impostos líquidos de subsídios $\left(\mathbf{T}=\left[\mathrm{t}_{\mathrm{ij}}\right]\right)$ e das importações $\left(\mathbf{M}=\left[\mathrm{m}_{\mathrm{ij}}\right]\right)$. Assim,

$$
\mathbf{A}^{\mathbf{p c}}=\mathbf{A}^{\mathbf{p b}}+\mathbf{M C}+\mathbf{M T}+\mathbf{T}+\mathbf{M}
$$

Uma vez que tal equação é uma identidade, é possível obter uma proporção das matrizes que estão do lado esquerdo da equação em (20) em relação à $\mathbf{A}^{\mathbf{p c}}$.

$$
\boldsymbol{\vartheta}^{\mathbf{p b}}=\frac{\left[\mathrm{a}_{\mathrm{ij}}^{\mathrm{pb}}\right]}{\left[\mathrm{a}_{\mathrm{ij}}^{\mathrm{pc}}\right]} ; \boldsymbol{\vartheta}^{\mathbf{m c}}=\frac{\left[\mathrm{mc}_{\mathrm{ij}}\right]}{\left[\mathrm{a}_{\mathrm{ij}}^{\mathrm{pc}}\right]} ; \boldsymbol{\vartheta}^{\mathbf{m t}}=\frac{\left[\mathrm{mt}_{\mathrm{ij}}\right]}{\left[\mathrm{a}_{\mathrm{ij}}^{\mathrm{pc}}\right]} ; \boldsymbol{\vartheta}^{\mathbf{t}}=\frac{\left[t_{i j}\right]}{\left[a_{i j}^{p c}\right]} ; \boldsymbol{\vartheta}^{\mathbf{m}}=\frac{\left[m_{i j}\right]}{\left[a_{i j}^{p c}\right]}
$$

em que $\boldsymbol{\vartheta}^{\mathbf{k}}$, em que $\mathrm{k}=\mathrm{pb}, \mathrm{mc}, \mathrm{mt}, \mathrm{t}, \mathrm{m}$ representa o mark-down em relação à matriz de absorção a preços do consumidor ${ }^{13}$. Ele representa uma proporção dos elementos $k$ em relação à $\mathbf{A}^{\mathbf{p c}}$, o que representa uma divisão elemento a elemento, de tal forma que $\boldsymbol{\vartheta}^{\mathbf{k}}$ possui a mesma dimensão $(n \times m)$, ou seja, nesse trabalho $(123 \times 67)$.

O cálculo dessas proporções corresponde ao primeiro passo para a estimação das matrizes, e é calculado para a matriz utilizada como base para a estimação. Nesse estudo, foi utilizada a MIP 2010.

Apesar das margens de comércio (MC), transporte (MT), dos impostos líquidos de subsídios (T) terem sido divulgadas por classificação de origem, na separação entre nacional e importado, optou-se por agregar tais informações ao utilizar como referência para o cálculo dos mark-downs.

\footnotetext{
13 Originalmente, em Grijó e Berni (2006) é estabelecida uma relação de mark-up ( $\left.\boldsymbol{\theta}^{\mathbf{p b}}\right)$ entre $\mathbf{A}^{\mathbf{p b}}$ e $\mathbf{A}^{\mathbf{p c}}$, ou seja, valorando a matriz de absorção a preços básicos em relação a preços de consumidor. Nesse caso, o equivalente à $\boldsymbol{\theta}^{\mathbf{p b}}=\frac{\mathbf{1}}{\mathbf{g}^{\mathbf{p}} \mathbf{b}}$. Feito isso, as demais proporções para as margens de comércio e transporte, impostos e importação são obtidas em relação à matriz de absorção a preços básicos. Entretanto, nesse estudo preferiu-se estimar todas as relações estruturais considerando apenas os mark-downs pelo ganho de informação e melhor desempenho em relação aos dados dessas matrizes.
} 
Ainda sobre estas margens, Grijó e Berni (2006) ressaltam que é necessária uma preparação prévia de para não gerar distorções nos mark-downs. Nos dados das MIP existem os produtos "Transportes" e "Comércio". Por outro lado, suas margens também são calculadas separadamente, presentes nas matrizes das Margens de Comércio e Margem de Transportes. Assim, para não gerar uma dupla contagem, deduz o valor destas margens do valor do produto valorado a preços básicos, para eliminar estas distorções.

O primeiro passo é obter o valor da soma das linhas dos produtos para a "Margem de comércio", exclusivamente o valor referente à linha do produto "Comércio". O mesmo deverá ser feito para a "Margem de transporte", somando todas as linhas, com exceção do produto "Transportes". O segundo procedimento é deduzir esta soma dos produtos "Transportes" e "Comércio" a preços do consumidor os valores das somas acimas mencionadas. Com isso, se obtém o novo valor destes produtos a preços básicos, líquido da reposição dos valores das margens de transporte e comércio, sob os quais serão calculados os dados estruturais.

\section{- Segundo passo: estimativa das novas matrizes a partir dos dados estruturais e TRUs}

Para a estimação da MIP 2014 a partir dos dados estruturais da MIP 2010, usa-se como postulado a hipótese que os mark-downs são inflexíveis em um período curto de tempo. Assim, a estimativa da MIP 2014 é calculada aplicando tais proporções para os vetores da tabela de usos e recursos a preços básicos $\left(\mathbf{a}^{\mathbf{p b}}\right)$, importação $(\mathbf{m})$, margem de comércio (mc), margem de transporte (mt) e impostos (t).

$$
\begin{gathered}
\widetilde{A}_{2014}^{p b}=\vartheta^{\mathrm{pb}} \otimes \mathrm{a}^{\mathrm{pb}} \\
\widetilde{M C}_{2014}=\boldsymbol{\vartheta}^{m c} \otimes \mathrm{mc} \\
\widetilde{M T}_{2014}=\boldsymbol{\vartheta}^{m t} \otimes \mathrm{mt} \\
\widetilde{T}_{2014}=\vartheta^{t} \otimes \mathrm{t} \\
\widetilde{M}_{2014}=\vartheta^{m} \otimes \mathrm{m}
\end{gathered}
$$

em que $\widetilde{\boldsymbol{A}}_{\mathbf{2 0 1 4}}^{\text {pb }}, \widetilde{\boldsymbol{M C}}_{\mathbf{2 0 1 4}}, \widetilde{\boldsymbol{M T}}_{\mathbf{2 0 1 4}}, \widetilde{\boldsymbol{T}}_{\mathbf{2 0 1 4}}, \widetilde{\boldsymbol{M}}_{\mathbf{2 0 1 4}}$ são as estimativas para o ano de 2014 para $\mathbf{A}^{\mathbf{p b}}, \mathbf{M C}, \mathbf{M T}, \mathbf{T}, \mathbf{M}$ e símbolo $\otimes$ é definido como o produto de Hadamard, em que é realizada a multiplicação de matrizes elemento a elemento.

Em alguns casos, não é possível calcular tais estimativas diretamente, pela existência de desajustes estruturais entre os dados do ano base e do ano a ser atualizado. Tal fato ocorre nos seguintes casos: (a) O valor na tabela de uso a preço de consumidor é nulo no ano base (2010) e positivo no ano de referência para a atualização (p.ex., 2014); (b) o valor de um recurso (da produção ou oferta a preços básicos, das importações, da margem de transporte, da margem de comércio e/ou dos impostos sobre produtos) é nulo no ano base (2010) e positivo no ano de referência para a atualização (p. ex., 2014).

Nos dois casos não é possível calcular-se os as estimativas a partir dos dados estruturais da MIP 2014, conforme descritos anteriormente, devendo ser adotados procedimentos Os procedimentos adotados foram os seguintes: no caso (a) é utilizada a razão entre o valor total do recurso específico do produto (produção a preços básicos, importações, margem de transporte, margem de comércio e impostos sobre produtos) e o valor total dos recursos do produto (oferta total a preços de consumidor); no caso (b) são utilizadas para cada célula na linha referente ao desajuste a razão entre o valor de cada tipo de uso na tabela de uso total a preços de consumidor e o valor total do recurso a preços do consumidor. Feito isso, é possível obter as estimativas iniciais para a MIP 2014.

\section{- Terceiro passo: estimativa das novas matrizes a partir dos dados estruturais e TRUs}

Uma vez estimadas as matrizes a partir das informações estruturais, é provável que este valor não seja compatível com o divulgado anualmente nas TRUs para o total das linhas e colunas dos preços de consumidor (margens de transporte e comércio, impostos líquidos de subsídios, valor da produção).

Para tanto, é necessário que haja esse ajuste. Tal balanceamento é realizado através do método RAS, um método de ajustamento bipropocional entre matrizes (MILLER; BLAIR; 2009). Através de um processo iterativo realizado por produto entre multiplicadores de linhas e colunas, da MIP estimada são balanceados, tornando a soma dos elementos iguais aos totais ao existente nos dados das TRUs.

Dentre as diferentes formas de uso do RAS, foi utilizado o RAS generalizado, denominado na literatura como GRAS. De acordo com Temurshoev et al (2013), este método foi originalmente apresentador por Günlüks Senesen e Bates (1988), sendo formalizado rigorosamente posteriormente por Junius and Oosterhaven (2003). A partir da adaptação de Termurshoev et al (2013) é possível utilizar este método mesmo na presença de linhas/colunas iguais a zero e/ou com elementos negativos. 
Apêndice B

Tabela 1 - Correspondência de Atividades Nível 19 e Atividades Nível 67 (SCN 2010)

\begin{tabular}{cl}
\hline Atividades Nível 19 \\
\hline $1 \quad \begin{array}{l}\text { Agricultura, pecuária, produção florestal, pesca e } \\
\text { aquicultura }\end{array}$
\end{tabular}
Código

191 Agricultura, inclusive o apoio à agricultura e a pós-colheita

192 Pecuária, inclusive o apoio à pecuária

280 Produção florestal; pesca e aquicultura

580 Extração de carvão mineral e de minerais não-metálicos

680 Extração de petróleo e gás, inclusive as atividades de apoio

791 Extração de minério de ferro, inclusive beneficiamentos e a aglomeração

792 Extração de minerais metálicos não-ferrosos, inclusive beneficiamentos

1991 Refino de petróleo e coquerias

2 Commodities industriais

1992 Fabricação de biocombustíveis

2091 Fabricação de químicos orgânicos e inorgânicos, resinas e elastômeros

2200 Fabricação de produtos de borracha e de material plástico

2491 Produção de ferro-gusa/ferroligas, siderurgia e tubos de aço sem costura

2492 Metalurgia de metais não-ferrosos e a fundição de metais

2500 Fabricação de produtos de metal, exceto máquinas e equipamentos

1091 Abate e produtos de carne, inclusive os produtos do laticínio e da pesca

3 Commodities agrícolas

1092 Fabricação e refino de açúcar

1200 Fabricação de produtos do fumo

1600 Fabricação de produtos da madeira

1700 Fabricação de celulose, papel e produtos de papel

1093 Outros produtos alimentares

1100 Fabricação de bebidas

1300 Fabricação de produtos têxteis

1400 Confecção de artefatos do vestuário e acessórios

$4 \quad$ Indústria Tradicional

1500 Fabricação de calçados e de artefatos de couro

1800 Impressão e reprodução de gravações

2092 Fabricação de defensivos, desinfetantes, tintas e químicos diversos

2093 Fabricação de produtos de limpeza, cosméticos/perfumaria e higiene pessoal

2300 Fabricação de produtos de minerais não-metálicos

3180 Fabricação de móveis e de produtos de indústrias diversas

2100 Fabricação de produtos farmoquímicos e farmacêuticos

2600 Fabricação de equipamentos de informática, produtos eletrônicos e ópticos

2700 Fabricação de máquinas e equipamentos elétricos

$5 \quad$ Indústria Inovativa

2800 Fabricação de máquinas e equipamentos mecânicos

2991 Fabricação de automóveis, caminhões e ônibus, exceto peças

2992 Fabricação de peças e acessórios para veículos automotores

3000 Fabricação de outros equipamentos de transporte, exceto veículos automotores

3300 Manutenção, reparação e instalação de máquinas e equipamentos

\begin{tabular}{|c|c|c|c|}
\hline 6 & $\begin{array}{l}\text { Produção e distribuição de eletricidade e gás, } \\
\text { água, esgoto e limpeza urbana }\end{array}$ & $\begin{array}{l}3500 \\
3680\end{array}$ & $\begin{array}{l}\text { Energia elétrica, gás natural e outras utilidades } \\
\text { Água, es goto e gestão de resíduos }\end{array}$ \\
\hline 7 & Construção & 4180 & Construção \\
\hline 8 & Comércio & 4580 & Comércio por atacado e varejo \\
\hline 9 & $\begin{array}{l}\text { Transporte, armazenamento, atividades auxiliares } \\
\text { dos transportes e correio }\end{array}$ & $\begin{array}{l}4900 \\
5000 \\
5100 \\
5280 \\
\end{array}$ & $\begin{array}{l}\text { Transporte terrestre } \\
\text { Transporte aquaviário } \\
\text { Transporte aéreo } \\
\text { Armazenamento, atividades auxiliares dos transportes e correio }\end{array}$ \\
\hline 10 & Alojamento e alimentação & $\begin{array}{l}5500 \\
5600 \\
\end{array}$ & $\begin{array}{l}\text { Alojamento } \\
\text { Alimentação }\end{array}$ \\
\hline 11 & Informação e comunicação & $\begin{array}{l}5800 \\
5980 \\
6100 \\
6280 \\
\end{array}$ & $\begin{array}{l}\text { Edição e edição integrada à impressão } \\
\text { Atividades de televisão, rádio, cinema e gravação/edição de some imagem } \\
\text { Telecomunicações } \\
\text { Desenvolvimento de sistemas e outros serviços de informação }\end{array}$ \\
\hline 12 & Ativ. financ. seguros e serv. relacionados & 6480 & Intermediação financeira, seguros e previdência complementar \\
\hline 13 & Atividades imobiliárias & 6800 & Atividades imobiliárias \\
\hline 14 & Atividades científicas, profissionais e técnicas & $\begin{array}{l}6980 \\
7180 \\
7380 \\
\end{array}$ & $\begin{array}{l}\text { Atividades jurídicas, contábeis, consultoria e sedes de empresas } \\
\text { Serviços de arquitetura, engenharia, testes/análises técnicas e P \& D } \\
\text { Outras atividades profissionais, científicas e técnicas }\end{array}$ \\
\hline 15 & $\begin{array}{l}\text { Atividades administrativas e serviços } \\
\text { complementares }\end{array}$ & $\begin{array}{l}7700 \\
7880 \\
8000\end{array}$ & $\begin{array}{l}\text { Aluguéis não-imobiliários e gestão de ativos de propriedade intelectual } \\
\text { Outras atividades administrativas e serviços complementares } \\
\text { Atividades de vigilância, segurança e investigação }\end{array}$ \\
\hline 16 & $\begin{array}{l}\text { Administração, saúde e educação públicas e } \\
\text { seguridade social }\end{array}$ & $\begin{array}{l}8400 \\
8591 \\
8691\end{array}$ & $\begin{array}{l}\text { Administração pública, defesa e seguridade social } \\
\text { Educação pública } \\
\text { Saúde pública }\end{array}$ \\
\hline 17 & Educação e saúde privada & $\begin{array}{l}8592 \\
8692 \\
\end{array}$ & $\begin{array}{l}\text { Educação privada } \\
\text { Saúde privada }\end{array}$ \\
\hline 18 & Artes, cultura, esporte e recreação & 9080 & Atividades artísticas, criativas e de espetáculos \\
\hline 19 & Outras atividades de serviços & $\begin{array}{l}9480 \\
9700\end{array}$ & $\begin{array}{l}\text { Organizações as sociativas e outros serviços pessoais } \\
\text { Serviços domésticos }\end{array}$ \\
\hline
\end{tabular}

Fonte: Elaboração própria a partir de IBGE 2016 e Torracca et al (2014) 
Apêndice C

Tabela 1 - Indicadores poder e sensibilidade de dispersão para produção, emprego e valor adicionado para o Brasil, anos 2010 e 2014

\begin{tabular}{|c|c|c|c|c|c|c|c|c|c|c|c|c|c|c|c|c|c|c|c|c|c|c|c|c|}
\hline \multirow{4}{*}{ Atividades nível 19} & \multirow{2}{*}{\multicolumn{4}{|c|}{\begin{tabular}{|c|} 
Produç̃õo \\
\end{tabular}}} & \multirow{2}{*}{\multicolumn{4}{|c|}{\begin{tabular}{|l|} 
Poder de dispersão \\
Emprego
\end{tabular}}} & \multirow{2}{*}{\multicolumn{4}{|c|}{$\begin{array}{l}\mathbf{V A} \\
\end{array}$}} & \\
\hline & & & & & & & & & & & & & \multicolumn{8}{|c|}{$\begin{array}{l}\text { ibilidade de dispersã } \\
\text { Emprego }\end{array}$} & \multicolumn{4}{|c|}{ 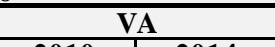 } \\
\hline & 2010 & & 201 & & 201 & & 2014 & & 2010 & & 2014 & & 2010 & & 201 & & 201 & & 2014 & & 2010 & & & 014 \\
\hline & Pd & Ord & & & Pd & Ord & & & & & & & & Ord & & & & & & & & & & \\
\hline $\begin{array}{l}1 \text { Agricultura, pesca e outros } \\
2 \text { groditios indurtiois }\end{array}$ & $\begin{array}{l}0,753 \\
346\end{array}$ & $\begin{array}{l}8 \\
1\end{array}$ & $\begin{array}{l}0,756 \\
3495\end{array}$ & & 2,246 & $\begin{array}{l}3 \\
5\end{array}$ & & & & & & & $\begin{array}{l}1,003 \\
3687\end{array}$ & & & & $\begin{array}{l}3,864 \\
0740\end{array}$ & & $\begin{array}{l}3,282 \\
0841\end{array}$ & & & 7 & $\begin{array}{l}1,364 \\
2,263\end{array}$ & \\
\hline & & $\begin{array}{l}1 \\
4\end{array}$ & 3,493 & $\begin{array}{l}1 \\
4\end{array}$ & $\begin{array}{l}1,671 \\
1872\end{array}$ & 5 & 1,707 & & 2,842 & $\begin{array}{l}1 \\
4 \\
4\end{array}$ & , & & $3,08 /$ & $\begin{array}{l}1 \\
5\end{array}$ & 3,103 & $\begin{array}{l}1 \\
6\end{array}$ & 0,760 & 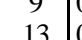 & 0,841 & $\begin{array}{l}8 \\
12\end{array}$ & 2,195 & 13 & 2,263 & 11 \\
\hline & & $\begin{array}{l}4 \\
2\end{array}$ & 3,195 & & 2,917 & 1 & 2,992 & & 2,717 & & 2,684 & & 2,289 & 2 & 2,252 & 2 & 1,881 & 3 & 2,022 & & $\begin{array}{l}1,613 \\
\end{array}$ & & $\begin{array}{l}1,611 \\
1\end{array}$ & $\begin{array}{l}13 \\
2\end{array}$ \\
\hline 5 Indú & & 3 & 2,420 & 3 & 1,208 & 6 & 1,310 & 6 & 1,970 & 3 & 1,934 & & 1,817 & 3 & 1,764 & 3 & 0,631 & 10 & 0,692 & 10 & 1,189 & 8 & 1,279 & 8 \\
\hline $6 \operatorname{Pr}$ & & 11 & 0,612 & 11 & 0,280 & 17 & 0,303 & 17 & 0,591 & 14 & 0,582 & 14 & 0,764 & 11 & 0,750 & 11 & 0,232 & 17 & 0,232 & 17 & 0,638 & 12 & 0,821 & 12 \\
\hline & & 15 & 0,285 & 15 & 0,293 & 16 & 0,325 & 16 & 0,284 & 19 & 0,289 & 19 & 0,269 & 18 & 0,261 & 18 & 0,324 & 16 & 0,360 & 16 & 0,277 & 18 & 0,278 & 18 \\
\hline $8 \mathrm{Co}$ & & 17 & 0,240 & 17 & 0,343 & 15 & 0,353 & 15 & 0,306 & 18 & 0,322 & 17 & 0,990 & 9 & 1,034 & 8 & 1,748 & 4 & 1,875 & & 1,506 & 3 & 1,351 & 1 \\
\hline & & 5 & 1,086 & 5 & 0,813 & 9 & 0,716 & 12 & 1,084 & & 1,037 & & 1,354 & 4 & 1,400 & 4 & 1,419 & 6 & 1,137 & & 1,432 & 6 & 1,510 & 3 \\
\hline & & 12 & 0,540 & & 0,867 & 8 & 0,861 & & 0,602 & & 0,618 & & 0,375 & 14 & 0,375 & 14 & 0,772 & & 0,771 & & & 17 & 0,439 & \\
\hline & & & 1,053 & & 0,625 & 12 & 0,717 & & 1,189 & & 1,185 & & 1,093 & & 1,045 & & 0,414 & 15 & 0,484 & 15 & 1,140 & & 1,208 & \\
\hline & & & 0,234 & & & 18 & 0,100 & 18 & & 16 & 0,328 & & & 12 & 581 & & 125 & & 0,139 & 18 & & 11 & 0,844 & \\
\hline & & 19 & 0,173 & 19 & 0,022 & 19 & 0,023 & 19 & 0,341 & 15 & 0,350 & 15 & 0,277 & 17 & 0,282 & 17 & 0,022 & 19 & 0,023 & 19 & 0,592 & 14 & 0,571 & \\
\hline & & & 0,765 & & 0,569 & 13 & 0,622 & 13 & 918 & & 0,941 & & 1,088 & & 1,108 & & 315 & & 0,911 & & 1,436 & & 1,371 & \\
\hline & & 1 & 0,6 & 10 & & & & & & & & & & & & 10 & & & & & & & & \\
\hline & & & 0,6 & & 138 & 10 & 0,736 & 10 & & & & & & & 25 & & & & & & & & & \\
\hline & & & & 13 & 0,711 & 11 & 0,748 & & & 2 & 0,642 & & , 353 & & & & & & & & & & & \\
\hline & & & & & & 14 & ,538 & 14 & & & 0,319 & & & & & & & & & & & & & \\
\hline & 422 & & & & & & & & & & & & & & & & & & & & & & & \\
\hline
\end{tabular}

Tabela 2 - Proporção (\%) do Poder de dispersão e sensibilidade de dispersão gerado no próprio setor e nos outros, para produção, emprego e valor adicionado no Brasil, anos 2010 e 2014

\begin{tabular}{|c|c|c|c|c|c|c|c|c|c|c|c|c|c|c|c|c|c|c|c|c|c|c|c|c|}
\hline \multirow{4}{*}{ 象 } & \multicolumn{12}{|c|}{ Poder de dispersão } & \multicolumn{12}{|c|}{ Sensibilidade de dispersão } \\
\hline & \multicolumn{4}{|c|}{ Produção } & \multicolumn{4}{|c|}{ Emprego } & \multicolumn{4}{|c|}{ VA } & \multicolumn{4}{|c|}{ Produção } & \multicolumn{4}{|c|}{ Emprego } & \multicolumn{4}{|c|}{ VA } \\
\hline & \multicolumn{2}{|c|}{2010} & \multicolumn{2}{|c|}{2014} & \multicolumn{2}{|c|}{2010} & \multicolumn{2}{|c|}{2014} & \multicolumn{2}{|c|}{2010} & \multicolumn{2}{|c|}{2014} & \multicolumn{2}{|c|}{2010} & \multicolumn{2}{|c|}{2014} & \multicolumn{2}{|c|}{2010} & \multicolumn{2}{|c|}{2014} & \multicolumn{4}{|c|}{2014} \\
\hline & Setor & Outros & etor & Outros & Setor & Outros & Setor & Outros & Setor & Outros & Setor & Outros & Setor & Outros & Setor & Outros & Setor & Outros & Setor & Outros & Setor & Outros & Setor & Outros \\
\hline 1 & 67,20 & 32,80 & $\overline{6,92}$ & 33,08 & 93,43 & 6,57 & 92,44 & 7,56 & 76,99 & 23,01 & 78,23 & 21,77 & 50,48 & 49,52 & 50,04 & 49,96 & 54,31 & 45,69 & 54,69 & 45,31 & 51,48 & 48,52 & 51,69 & 48,31 \\
\hline 2 & & 30,18 & & & & & & 65,13 & & & & & & & & & & & & 29 & 71,57 & 28,43 & 72,00 & 00 \\
\hline 3 & & 48,18 & & 49,3 & 24,52 & 75, & & 72,78 & & 63, & & 64, & & 20, & & & & 19 , & & 18 & 79,48 & 52 & 81,56 & 8,44 \\
\hline 4 & & 41,98 & & & & 44 & & 40,83 & 46 & 50 & & 49,56 & 67 & & & & 83 & 13 , &, 58 & 12, & 83,41 & 16,59 & 83,94 & 5,06 \\
\hline 5 & & 39,14 & & & 37,50 & & & 60,54 & 65 & & & 50 , & & & & & & & & & & & & 9,46 \\
\hline 6 & & 29 , & & & & & & 48, & & & & 34 & & 49,55 & & & 88 & & & & 51,80 & 48,20 & 14 & 9,86 \\
\hline 7 & & & & & & & & 26,43 & & & & & & & & & & & & & & & 66,39 & 3,61 \\
\hline 8 & & & & & & & & & & & & & & & & & & & & & & & & 16 \\
\hline 9 & & & & & & & & 33 & 66,61 & & 68,29 & & & & & & & & & & & & & \\
\hline 10 & & & & & & & & & & & & & & & & & & & & & & & 49 & 51 \\
\hline 11 & & & & & & & & & & & & & & & & & & & & & & & & 26 \\
\hline 12 & & & & & & & & & & & & & & & & & & & 31,07 & 68 & 29,37 & 63 & 31,07 & 68,93 \\
\hline 13 & & & & & & & & & & & & & & & & & & & & & & & & 23 \\
\hline 14 & & & & & & & & 31 & & & & & & & & & & & 46 , & 53 & 46,75 & 53 & 46,39 & 53,61 \\
\hline 15 & & & & & & & & 11 & & & & & & & & & & & & 44 & & 19 & 03 & 42,97 \\
\hline 16 & & & 71 , & & & & & 27 & & & & & & & & & & & & & & & 12 & 88 \\
\hline 17 & & 31 , & 71,92 & & & & & 16, & 71, & & 76 & & & & & & & & & & 12 & & 06 & 94 \\
\hline 18 & & & & & & & & & & & & & & & & & & & & & & & & 13,47 \\
\hline 10 & 4,25 & 25,75 & 76,05 & & 95,39 & 4,61 & 95,56 & 4,44 & 81,25 & 18,75 & 83,04 & 16,96 & 8,07 & 11, & 88,68 & 11,32 & 95,46 & 4,54 & 95,02 & 4,98 & 92,14 & 7,86 & 92,19 & 7,81 \\
\hline & - & & 8,13 & 1,0 & 4,70 & 35,25 & 65,55 & 4,45 & 68,37 & 31,63 & 88,60 & 1,40 & $\Delta, 45$ & 4,57 & 65,93 & 4,0 & 10,3 & 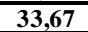 & 0,9 & 5,0 & 9,0 & & 00,0 & \\
\hline
\end{tabular}

Fonte: Elaboração própria com base em IBGE (2016a, 2016b) e estimativas realizadas nesse estudo. 